\title{
Nordic green bond issuers' views on the upcoming EU Green Bond Standard
}

\author{
Linn Björkholm, Othmar M. Lehner*
}

Hanken School of Economics

\section{ARTICLE INFO}

\section{Article history:}

Received 04 November 2021

Revised 09 December 2021 and 24

March 2021

Accepted 23 June 2021

Published 07 October 2021

Keywords:

Green bond

Nordics

Green bond issuer

EU Green Bond Standard

EU GBS

Standardisation

\section{ABSTRACT}

The green bond market is growing and becoming increasingly important in green finance and for the transition to a low-carbon economy. Still, the green bond market is to a large extent unstandardised. There is no commonly agreed definition of the term 'green'. This has been seen as one of the biggest challenges when it comes to the development of the green bond market. The need of a unified EU standard has been raised and as an effect the establishment of the EU Green Bond Standard is now in development. However, new standards might not only bring advantages, but also challenges. Striking the right balance of strictness might be hard. The research has been conducted through qualitative method with semi-structured interviews. Nine interviews were held during November and December 2020. The data was then analysed through thematic coding in order to find patterns of meaning. The results show that Nordic green bond issuers overall are positive towards the EU Green Bond Standard. The EU GBS has a good aim, to harmonise and enlarge the green bond market. However, the standard brings challenges that are to a large extent known challenges which the EU GBS aims to address, such as labour intensive reporting processes, lack of initiative and reputational risk. Also, it is argued that the standard is not fair and applicable for all the countries and companies. Countries national laws may not always go hand in hand with the standard. For example, the requirements for green buildings are seen as challenging in the Nordics. If these challenges are not taken into consideration, Nordic green bond issuers fear that the market will not grow, but instead decrease. Additionally, Nordic green bond issuers argue the adoption of the EU GBS is not a guarantee for issuers. Bigger institutes are seen to be early adopters. For other issuers investor requirement and positive impact on their company reputation is seen as the key drivers for adoption of the standard.

* Corresponding author. 


\section{Introduction}

One of the biggest challenges of the global community today is climate change. To respond and tackle this issue, the Paris Agreement was concluded in 2015, where 195 countries came together to fight against climate change and limit global warming to below two degrees (European Commission e n.d). The 17 Sustainable Development Goals (SDGs) were also set out in 2015. They aim to protect the planet, end poverty and ensure that people can live within peace and prosperity by 2030 (United Nations n.d.). To achieve the goals that have been set out in the Paris Agreement and the SDGs, a shift towards a climate-resilient, sustainable economic system that can mitigate climate change and stop the reduction of natural capital such as water, land, air and biodiversity needs to be done. There is a need for a reorientation of capital flows towards sustainable investments and therefore green finance naturally has become more important. (TEG 2019)

Green finance has grown during the past years and is now an important part of the economy. Economies are becoming greener thanks to the change in business culture and consumption patterns and there is a bigger demand for socially responsible investment options. The EU has responded on the climate change and environmental degradation challenges with a new growth strategy called The European Green Deal. The European Green Deal is the EUs plan towards a sustainable EU economy. This strategy includes an action plan, containing an establishment of an EU Green Bond Standard. Green bonds represent a small, but growing share of the bond market and are seen to become more important in financing assets that are needed for the transition to a low-carbon economy and the targets set in the Paris Agreement and the SDGs (European Commission b n.d.). (European Commission a n.d.)

When it comes to the green bond market, Nordic actors are frontrunners in promoting market integrity. According to external reviews they are demonstrating best practice, they are pushing investor standards and they are seen as leading in the international dialogue (CBI 2018). The Nordic countries are also seen as pioneers when it comes to using green bonds to accumulate capital for sustainable goals (Nassiry 2018). In order to understand the impact that the EU Green Bond Standard might have, it is of interest to look into the leading market actors' thoughts about the standard.

To understand the Nordic green bond issuers' views on the upcoming standard, the objective of this section is to explore and bring up the most central aspects regarding advantages, challenges and adoption of the standard. The empirical research has been conducted as qualitative research using semi-structured interviews. The data set consists of nine interviews conducted in November and December 2020. The data has been analysed though thematic coding as it gives the opportunity to identify and organize the data and find patterns of meaning.

The results show that Nordic green bond issuers overall are positive towards the EU Green Bond Standard. The EU GBS has a good aim, to harmonise and enlarge the green bond market. However, the standard brings challenges that are to a large extent known challenges which the EU GBS aims to address, such as alignment to the Taxonomy, lack of initiative and reputational risk. Also, it is argued that the standard is not fair and applicable for all the countries. Countries have their national laws, which may not always go hand in hand with the standard. For example, will Nordic green bond issuer have a challenge to issue green bonds with regards to green buildings as the requirements for a certain certificate level is higher than in other countries. If these challenges are not taken into consideration, 
Nordic green bond issuers fear that the market will not grow, but instead decrease. Additionally, Nordic green bond issuers argue the adoption of the EU GBS is not a guarantee for issuers. Bigger institutes are seen to be early adopters, while for other issuers the adoption depends on investor requirements.

\section{Problem area}

Even though green bonds have been on the market for over a decade, they are still unstandardised to a large extent (EIB 2016). The concept as well as the definition of being "green" differs across the world (CBI 2018). The guidelines for green bonds consist of voluntary frameworks, and different companies and governments have different methods when classifying their operations and securities (TEG 2019). This causes issues because of the inconsistent information leading to a lack of comparability, which becomes misleading and harder for reporters, investors and regulators to use (Brunsson \& Jacobsson 2000). In order to for the green bond market to grow, the need of clearer standards that harmonize products and lower costs across international markets has been argued (UNEP et. al. 2016).

The European Commission has stated that the lack of a commonly agreed definition of green and a uniform green standard is one of the biggest problems when it comes to the development of the green bond market (TEG 2019). The need for strong signals regarding the directing of financial and capital flows to green investments was emphasised in the European Green Deal (European Commission a n.d). Consequently, the Commission's High-Level Group on Sustainable Finance (EU HLEG 2018) included in their final report a recommendation that an EU Green Bond Standard (EU GBS) should be established in order to strengthen the development of the green bond market.

The new EU Green Bond Standard aims to bring opportunities both for the market and the issuers. However, as with all new standards there might not only be advantages, but also challenges. One big challenge with standardisation is to strike a balance. If the standards that regulate the green bond markets are too strict, it can become too costly for the issuers and result in a slow market growth. It is, however, important to ensure transparency as this creates more confidence for the investors and can expand the investor-base. If trust is misused and investors are misled even by only one issuer, the entire market could be affected and lose credibility. (Brunsson \& Jacobsson 2000, Talbot 2017)

According to KPMG (2019), the positive outcome from the standard is seen as bigger than negative outcomes. Even though the standard might cause additional work, both issuers and investors can benefit from the well-defined protocol for issuance of green bonds. For example, issuers' and investors' reputation and ESG-reporting can be strengthened. However, Wong (2004) studied the challenges in implementing the international standards IFRS and ISA and argues that there are benefits with standards, but they can only be fully realised when the challenges have been addressed.

One of the aims of the EU Green Bond Standard is to make the green bond market grow by bringing more quality and transparency to the market (TEG 2020). What can be seen as a challenge is striking the right balance of requirements in order for the market to grow and not slow down. Hence, it is of high importance to investigate what the green bond issuers' thoughts about the standard are. Furthermore, as the Nordic green bond issuers are seen as frontrunners in the market and highly competent, the focus will lie on their views. 
Research question and purpose

This section's research aims to answer the research question:

RQ: What are the Nordic green bond issuers' views on the upcoming EU Green Bond Standard?

The research question can further be divided into three sub questions:

1. What kind of advantages do Nordic green bond issuers see with the EU Green Bond Standard?

2. What kind of challenges do Nordic green bond issuers see with the EU Green Bond Standard?

3. What do Nordic green bond issuers think about the adoption of the EU Green Bond Standard?

The purpose of the research is to bring forth the issuers' thoughts about the standard in order to bring value to green bond issuers in the Nordics and outside of the Nordics by sharing thoughts and knowledge. Furthermore, it may as well be of interest for anyone concerned or interested in green bonds and its development on the market. The findings aim to help stakeholders involved in the adoption of the standard to understand the advantages and challenges it may bring of the coming standard. The results are also applicable to the overall establishment and adoption of standards and hence contributes to the research of new standards.

\section{Delimitations and limitations}

Delimitations have been made by only including the Nordic countries, as they are seen as frontrunners in green finance and in the green bond market. Furthermore, the interviews have been made in November and December 2020 and the data will therefore only include what has been done until then.

\section{Key terms and definitions}

In this section, some of the key terms and definitions will be presented and briefly explained in order to support the reader.

Green Bond. A bond is a debt security that is sold by governments and corporations. A debt security is a legal contract for money owed that can be bought and sold between different parties. A green bond is a type of bond that channels its funds to projects that benefit the environment while simultaneously raising awareness of environmental risks. (The world Bank 2015)

Green bond issuer. Any organisation that has bonding authority can issue a green bond. Issuers of bonds can be private companies, supranational institutions (for example multilateral banks) and public entities (such as state, municipal or federal) (The World Bank 2015).

Standard. Standards are a technical specification defining requirements for products, production processes, services or test-methods (European Commission c n.d.). They are voluntary and not legally binding and can be used to support legislation and policies. 
EU Green Bond Standard. The European Commission's upcoming standard on green bonds, which European green bond issuers can choose to align their green bonds with (European Commission b 2019).

\section{Outline}

The paper is structured as follows; the first section introduces the EU Green Bond by explaining its importance and relevance. It brings up the research problem, research question and the purpose of the study. After that the limitations are presented, as well as a short list of key terms and definitions. The two following sections present relevant theory for the study to give the reader needed background information. The first theory section focuses on green bonds, the legitimacy theory and standardisation. The following section gives the reader an introduction to the EU Green Bond Standard, how the establishment process has proceeded, what the draft looks like and possible outcomes from it.

Section four presents previous research about adoption of new standards. It is divided according to the research question's sub questions and a conclusion can be found in the end. Section five introduces the methodology used in the section. The section starts with the research design, followed by the sample, the collection of data, and how the data will be analysed. The section is concluded with research ethics and details on how the quality of the research was ensured. In the sixth section the empirical findings of the study are presented. The section is divided into themes found through thematic coding. The seventh section analyses the empirical findings from section five and connects it to theory and the literature presented in section two to four. It is divided by the sub research questions. The final section presents the five key conclusions and suggests further research.

\section{Theoretical Background}

This section will go through the theoretical frameworks of this study. Starting with introducing green bonds and relevant concepts, it will be followed by standards and their benefits and challenges. Lastly the legitimacy theory will be presented and its relevance for this study will be explained.

\section{Green Finance}

Green Finance includes sustainability considerations in financial decision-making. This means that projects are more climate neutral, circular and energy- and resource-efficient. By integrating sustainability considerations into finance, factors like the impact of natural disasters, environmental issues and social issues, that can affect the economy and the financial markets, can be reduced. (European Commission a 2019)

Green finance's position in the economy has developed a lot during the years. KPMGs (2017) Survey of Corporate responsibility $(\mathrm{CR})$ reporting done in 2017 showed that $\mathrm{CR}$ reporting had grown from $12 \%$ to $75 \%$ between year 1993 and 2017 when looking at the 100 biggest companies in the world. Comparable numbers for the 250 largest companies are from $35 \%$ to $93 \%$. This can be argued due to the modern business environment putting pressure on managers to explore the increased corporate responsibility (Werther \& Chandler 2011). This has meant a shift in stakeholders' values and needs and therefore a shift in companies' ways of doing business and value creation (Liu 2020). This can be explained with the stakeholder's theory that calls attention to the importance of not only satisfying 
the expectations of the shareholders of a company, but also understand the different stakeholders' interests (Freeman 1984).

\section{Green bonds}

Green bonds are a part of green finance. A bond is a debt security that is sold by governments and corporations. A debt security is a legal contract for money owed that can be bought and sold between different parties. Its purpose is to raise money from investors today in return for promised payments in the future. A green bond is a type of bond that channels its funds to projects that benefit the environment at the same time as they raise awareness of environmental risks. The World Bank was first to issue a green bond in 2008 and since then number of issued green bonds has grown largely. The specific use of the fund distinguishes green bonds from regular bonds. It also counts as a part of green finance. (The world Bank 2015)

According to Preclaw and Bakshi (2015) there are two different kinds of green bonds: unlabelled green bonds and labelled green bonds. Unlabelled green bonds are conventional bonds issued by companies whose business are aligned with environmental projects. Labelled green bonds on the other hand are bonds designed by the issuer to be green. When only green bonds are mentioned in this section, it refers to the labelled green bonds.

International Capital Market Association (ICMA) (2018) has further divided the labelled green bonds into four different categories according to the Green Bond Principles (GBP). All of the four types are aligned with the GBP. The first one is a Standard Green Use of Proceeds Bond. This one can be described as a standard resource-to-theissuer debt obligation. The second one is called Green Revenue Bond and is a non-resource-to-the-issuer debt obligation. Here the bonds' credit exposure is the pledged cash flow of the revenue streams, taxes, fees etc. These bonds' proceeds may go to either related or unrelated Green Project(s). The third type is Green Project Bond. This bond can be related to a single or multiple Green Project(s) and the investor has direct exposure to the project(s) risk with or without potential recourse to the issuer. The last type of green bond is a Green Securitised Bond. This bond is collateralised by either one or more specific Green Project(s). This includes, but is not limited to covered bonds, asset-backed securities, mortgage-backed securities and other structures.

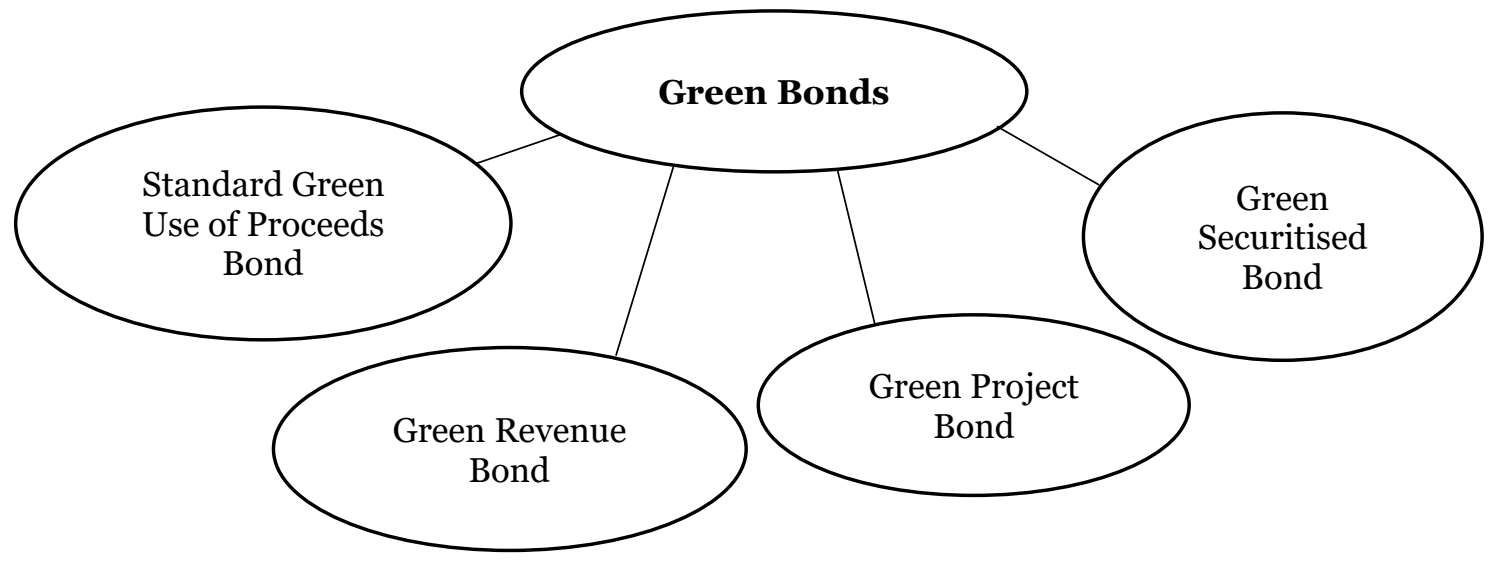

Figure 1. Types of Green Bonds according to the Green Bond Principles 
Green bonds enable issuers to reach different investors and at the same time promote their environmental character. The demand of green bonds has grown bigger and so has the group of the investors. In the beginning, the first investors were institutional investors in Europe and investors with strong environmental focus in the United States. Now the group of investors has broadened and includes asset managers, companies, foundations and religious organisations. Many investors invest in green bonds within their existing portfolios in order to respond to their buyers' interest in supporting climate-focused activities. Green bonds can therefore be used to communicate stakeholder's commitment to supporting environmentally friendly investments. (The World Bank 2015)

\section{Green Bond Principles}

Green Bond Principles (GBP) were established in 2014 by a group of large investments banks and the ICMA as a response to concerns regarding transparency of green bonds. The GBP are voluntary process guidelines which clarify the approach for issuance of a Green Bond by recommending transparency and disclosure and promoting integrity in the development of the Green Bond market. The principles are intended to support several market participants, supporting issuers with guidance in launching credible Green Bonds, ensuring investors that necessary information is available and trustworthy in order for the investors to be able to assess the environmental impact the Green Bond investment has and assisting underwriters by moving towards standard disclosure. By supporting the market participants with the needed information, the guidelines aim to increase capital to projects that contribute to environmental sustainability. (ICMA 2018)

Issuance of green bonds aligned to the GBP are meant to provide an investment opportunity that is acknowledged with transparent green credentials. The principles recommend that the use of green proceeds should be reported by the issuers. This aims to enhance the transparency as the tracking of the funds which goes into the environmental projects is improved. At the same time the insight of the estimated impact of the projects may be seen easier. (ICMA 2018)

The GBP offers high level classification for eligible Green Projects while keeping in mind the diversity of the current views and the constant development of environmental issues and consequences. Additionally, when needed alignment with other parties that offers complementing definition, standards and taxonomies needed when determining the project's environmental sustainability is made. The principles encourage market participants to use this as a base in order for them to develop their own practices. They also emphasise a wide set of relevant criteria that can complement their practises. (ICMA 2018)

The GBP consist of four components: (1.) Use of Proceeds (2.) Process for Project Evaluation and Selection (3.) Management of Proceeds (4.) Reporting (ICMA 2018). The Principles however do not provide any details on the definition of green.

\section{Green Bond Market}

The Green Bond market has grown rapidly from its start in 2007 when the World Bank issued the first green bond (The world Bank 2015). At the beginning green bond issuers were mainly development banks and agencies, now the market has spread into all debt capital asset classes and reflects the overall debt market (TEG 2019). In June 2019 a 
milestone in the green bond market was reached when the green bond issuance for the year had exceeded USD 100 million within the first half of the year. By the end of the year, the issuance had reached USD 250 billion, which is equivalent to $3.5 \%$ of the total global issuance (USD 7.15 trillion) (BIS 2020). In year 2020 the issuance of green bonds again toped the records with an issuance of USD 270 billion (Climate Bonds Initiative 2021). Still the green bond market is small compared to the overall fixed income market (S\&P global 2019).

The standardisation of the green market is still in progress. A big improvement was done in 2014 when the GBP were established and published by several banks together with ICMA. The GBP was adopted by the majority of the market actors, which further strengthens the green bond market (TEG 2019).

\section{Barriers to Green Bond market development}

According to TEG (2019) currently the Green bond market development are facing six barriers: Lack of eligible green projects and assets, Issuer concerns with reputational risk and green definitions, Absence of clear economic benefits for issuers, Complex and potentially costly external review procedures, Labour intensive reporting procedures and Uncertainty on the type of assets and expenses that can be financed.

Lack of eligible green projects and assets: The green bond demand from investors is currently higher than issuers capacity to identify eligible green projects and assets. This is not only due to lack of real green investments, but also because of the uncertainty of what is green. Therefore, direct policy measures are seen as needed in order to strengthen real economy investments in green assets and infrastructure.

Issuer concerns with reputational risk and green definitions: The fact that the definition of green assets and project is not defined prevents some issuers from issuing green bonds. This is due to the fare of for example calling something green that later will be deemed as "insufficiently green". The result may then be negative comments from the market, ex. media, non-governmental organisations or shareholders, which will impact negatively on issuers' reputation.

Absence of clear economic benefits for issuers: The pricing benefits of a green bond for the issuers are, if any, small and not universal. When issuing a green bond there are some additional costs, for example fees for external reviewers, fees regarding the green bond process and reporting. The companies usually then experience the benefits of a diversification in their investor base and a higher demand.

Complex and potentially costly external review procedures: Today there is a broad range of market practices for the external reviews. Also, the firms who provide the external reviews services have a diverse level of expertise regarding environmental matters. This can lead to quality control issues, duplications and increased costs.

Labour intensive reporting procedures: When issuing a green bond, it is market practice to report on the projects and activities that are being financed. This report includes for example information about the projects' environmental impacts. However, the preparation and maintenance of the report is often seen as an added burden for the issuers and makes green bond issuance less attractive.

Uncertainty on the type of assets and expenses that can be financed: The classification of green use of capital is still not clarified. By clarifying the types of assets and expenses that can be financed, more projects can be financed in a legitimate and controlled way. 


\section{Greenwashing}

TerraChoice (2007) has defined greenwashing as "the act of misleading consumers regarding the environmental practices of a company or the environmental benefits of a product or service." According to Delmas and Burbano (2011) greenwashing can as well be seen as "the intersection of two firm behaviours: poor environmental performance and positive communication about environmental performance". Delmas and Burbano (2011) have come to this conclusion by dividing firms into two categories of environmental performance: poor environmental performers called brown firms, and good environmental performers called green firms. While no firm would communicate negatively of their bad environmental performance, brown firms are either choosing to remain silent or to represent their bad environmental performance in a positive light. The same logic is applied to green firms. This is described below in figure 2 .

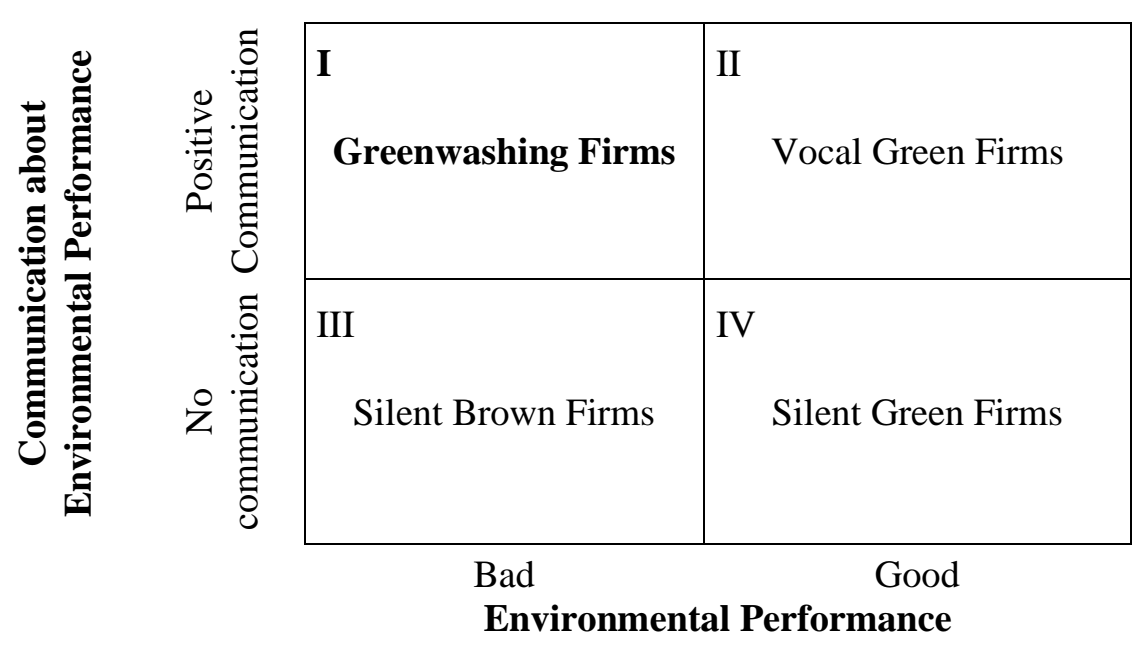

Figure 2. Delma and Burbano 2011 typology of firms based on environmental performance and communication.

Greenwashing is highly relevant when it comes to green bonds and it is seen as one of the most recognised risks (Ludvigsen 2015). This relates as well to one of the barriers to green bond market development described in section 2.2.1.1. Issuers concerns with reputational risk and green definition. As already stated, while the green bond market is to a large part unstandardised, this causes lack of transparency and consistency. Due to lack of consistency and no unified definition of what green is, there is a wide range between green activities. As Ludvigsen (2015) described “One investor's idea of a "dark green" is another's "light green", "vanilla," or even "brown"."

Issuing bonds

When it comes to issuing a bond there are requirements. Issuers of bonds can be private companies, supranational institutions (for example multilateral banks) and public entities (such as state, municipal or federal). The entity that has issued a bond is required to disclose financial information to regulators, investors and rating agencies. When it comes to issuing green bonds, any organisation that has bonding authority can issue one. Usually there are additional costs for green bonds associated with disclosure and reporting requirements occur. These costs could be compensated 
by a greenium. A greenium is the market premium to the price of the bond. (Fatica, Panxica \& Rancan 2019, The World Bank 2015)

The process of issuing a green bond can look differently. For example, The World Bank (2015) green bond process is divided into four categories:

1. Define project selection criteria

2. Establish project selection process

3. Earmark and allocate proceeds and lastly

4. Monitor and report

First the issuer needs to define which kind of green project it supports, for example the transition to low-carbon development and climate-resilient growth. These selection criteria are then usually assessed and reviewed by external experts in order to assure the investors that the general accepted technical definitions are met. After this the projects go through a review and approval process. This includes early screening, identifying and managing potential environmental impacts and obtaining approval needed from the issuers Board of Executive Directors. Further on the issuer should earmark and allocate proceeds to the green bond. Lastly, all this should be monitored and reported. (The World Bank 2015)

Many issuers have their own green bond framework. These consist of information regarding the green bond, especially information on future issues and which kind of projects that will be financed. Green Bond Framework is voluntary and there is no unified practice on them. (TEG 2019)

\section{Green Projects}

As stated in the section 2.2 green bonds proceeds are located to green projects. The designated green projects should provide environmental benefits. These benefits are then assessed and if possible quantified by the issuer. The ICMA (2018) has in their GBP categorised several broad categories of green projects that contribute to environmental objectives like climate change mitigation, climate change adoption, biodiversity conservation, natural resource conservation and pollution prevention and control. Green projects also include other supporting expenses, for example research and development. Furthermore, green projects can be related to more than one category or environmental objective. The Green Project categories can be seen in figure 3. 


\begin{tabular}{ll}
\hline Green Project: & Includes: \\
\hline Renewable energy & Production, transmission, appliances and products \\
Energy efficiency & New and refurbished buildings, energy storage, district heating, smart grids, \\
& appliances and products \\
Pollution prevention and control & $\begin{array}{l}\text { Reduction of air emissions, greenhouse gas control, soil remediation, waste } \\
\text { prevention, waste reduction, waste recycling and energy/ emission-efficient } \\
\text { waste to energy } \\
\text { Environmentally sustainable }\end{array}$ \\
management of living natural resources & $\begin{array}{l}\text { Environmentally sustainable agriculture; environmentally sustainable animal } \\
\text { husbandry; climate smart farm inputs such as biological crop protection or } \\
\text { drip-irrigation; environmentally sustainable fishery and aquaculture; } \\
\text { environmentally sustainable forestry, including afforestation or reforestation, } \\
\text { and preservation or restoration of natural landscapes) }\end{array}$
\end{tabular}

Terrestrial and aquatic biodiversity Protection of coastal, marine and watershed environments conservation

\section{Clean transportation}

\author{
Sustainable water and wastewater \\ management
}

\section{Climate change adaptation}

Eco-efficient and/or circular economy adapted products, production

technologies and processes

\section{Green buildings}

Electric, hybrid, public, rail, non-motorised, multi-modal transportation, infrastructure for clean energy vehicles and reduction of harmful emissions

Sustainable infrastructure for clean and/or drinking water, wastewater treatment, sustainable urban drainage systems and river training and other forms of flooding mitigation)

Information support systems, such as climate observation and early warning systems

Development and introduction of environmentally sustainable products, with an eco-label or environmental certification, resource-efficient packaging and distribution

That meet regional, national or internationally recognised standards or certifications

Figure 3. Green Projects according to GBP 
When issuing according to the GBP the Green Bond issuer needs to communicate to the investors about the project evaluation and selection and ensure that the project is within the Green projects categories that can be seen in figure 3. Furthermore, issuers should communicate how they have taken risks associated to the project into consideration. It is also recommended to have an external review done on the project evaluation and selection. (ICMA 2018)

\section{Proceeds}

The proceeds coming from a green bond can be used to finance or refinance green project. GBP has recommended that issuers should provide an estimate of the share of financing verses re-financing. The net proceeds or an amount equal to the net proceeds should be tracked. This can be done for example by crediting the proceeds to a sub-account or moved to a sub-portfolio. This should as well be verified in an internal process that can be linked to Green Projects lending and investments operations by the issuer. (ICMA 2018)

During the time when the green bond is outstanding the balance of the tracked net proceeds should be adjusted periodically in order to match allocation made during that time period to green project. GBP encourage use of third party to verify the internal tracking method and the allocation of the proceeds. Green bond proceeds can be allocated through a bond-by-bond approach or a portfolio approach. When using a bond-by-bond approach, specific proceeds are allocated to specific green projects. Portfolio approach on the other hand works like two ponds that are connected to each other. One pond consisting of all the green proceeds and one pond consisting of all the green projects, which means the assets are not allocated to specific projects. (ICMA 2018)

The term grandfathering is relevant when it comes to green bonds. Grandfathering relates to the rule of first possession. It means that if a modification of a rule related to a certain investment or investment technique is done, the investment actions that has been done before that certain date will remain subject to the old rules (Scott 2003). This can for example be relevant if the requirements for what a green project is or what counts as a green proceed changes. If then the old green bonds are grandfathered, the alteration of the rule will not affect already existing green bonds.

\section{Reporting}

According to the GBP green bond issuers should make and keep information regarding the use of proceeds. This information should be available, up to date and renewed annually until the allocation has been fulfilled. A list of the projects receiving green bond proceeds should be included in the annual report. This list should as well include a short description of the projects, the amount that has been allocated and expected impacts from the projects. When reporting on green bonds, it is recommended to use qualitative performance indicators and if possible quantitative performance measures. The key methodology and assumptions used for the quantitative should as well be disclosed. Furthermore, GBP encourages issuers who are able to monitor the impact of the projects, to do so and include that in the reporting. (ICMA 2018) 
External review

An external review of the Green Bond is voluntary and can be done in order to confirm alignment with guidelines. The reviews can both be partial, only covering certain aspect of the green bond, or full, looking into all components (ICMA 2018). According to GBP, external reviews can be divided into four groups:

Second Party Opinion. This can be issued by an institution with environmental knowledge and that is independent from the issuer. A second party opinion can confirm the alignment with a principle or standard. Furthermore, it can include an evaluation of the strategy, policies and processes regarding environmental sustainability and the features regarding green projects.

Verification Independent verification can be obtained when complaining to a set of criteria. Verification can be directed to internal or external standards or claims.

Certification Green bonds, green bond framework or use of proceeds can get a certified against a green standard or a label. This ensures the alignment with the standard or label and is usually tested by accredited third parties.

Green Bond Scoring/Rating Qualified third parties can evaluate and assess green bonds, green bond framework or other key features through a scoring or rating mythology.

\section{Legitimacy theory}

The legitimacy theory has been derived from the concept of organisational legitimacy. Dowling and Pfeffer (1975) described it as "a condition or status which exists when an entity's value system is congruent with the value system of the larger social system of which the entity is a part. When a disparity, actual or potential, exists between the two value systems, there is a threat to the entity's legitimacy.". This theory argue that organisations seek to ensure that they operate according to their respective societies' norms and bounds. Furthermore, it means that there is a "social contract" between a company and the society it operates in. (Guthrie et al 2006)

The legitimacy theory can be seen as a mechanism that supports organisations in implementing and developing voluntary social and environmental disclosures which enables the organisation to fulfil their social contract. Several studies have been made regarding the applicability of the legitimacy theory on CSR disclosures. These studies (for example Adams, Hill and Roberts 1998, Campbell, Craven and Shrives 2003, Deegan, Rankin, and Tobin 2002) acknowledge the legitimacy theory's applicability. Therefore, the Legitimacy theory is often used to describe environmental and social disclosures. (Burlea-Scgiopoiu and Popa 2013, Guthrie et al 2006)

When it comes to green bonds and to an EU Green Bond Standard, the legitimacy theory is relevant because standards can create trustworthiness (Brunsson \& Jacobsson 2000). Fisher et al. (2017), Suchman (1995) and Zimmerman and Zeitz (2002) argues that creating legitimacy is an effective way to overcome the liability of newness and to assure positive outcomes for organisations in the future. While green bonds are still relatively new on the market, it is of high importance to create legitimacy. 


\section{Standards}

Standards has been defined by the European Commission (c n.d.) as "technical specifications defining requirements for products, production processes, services or test-methods". They are voluntary and not legally binding and can be used to support legislation and policies. In other words, they provide rules but cannot claim hierarchical authority or impose sanctions. They can become binding if this is stated in legislation or in a contract. (Brunsson \& Jacobsson 2000, European Commission c n.d.)

Standards can be seen as a way of creating order in the modern world, which would not be possible without them. They are an instrument of control and can be explained as general advices which are offered to a large number of possible adopters. People and organisations worldwide follow the same standards, which creates co-operation and co-ordination globally. Even among people and organisations that are far apart from each other standards can create homogeneity and similarity. Standards aim to ensure interoperability and safety, reduce costs and facilitate companies' integration in the value chain and trade. (Brunsson \& Jacobsson 2000, European Commission c n.d.)

The majority of the standard issuers are organisations in the private sector, private people and non-governmental organisations. Standards are usually developed for an industry and they follow basic principles like openness, transparency, consensus and non-discrimination. They are especially common and important on the global stage. This is due to that there are no world state with legislative power and therefore there is a need for standards. (Brunsson $\&$ Jacobsson 2000)

Standardisation is a form of regulation. It can both be argued as beneficial and disadvantageous. Below are the main benefits and challenges with standardisation.

\section{Benefits with standardisation}

Benefits with standards are similar to rules and regulations, they assist with communicating information. Knowing that a party complies with a familiar standard already gives the other parties around a great deal of information which benefits everyone as less questions need to be asked. It is an effective way of transmitting information and it improves the comparability of information. Furthermore, even though we are not familiar with the content of the standard, often just knowing that a party will comply with it will make the part more trustworthy. Some standards as well require a third party to certify that the standard has been followed. This as well creates trustworthiness. (Brunsson \& Jacobsson 2000)

Standards are also an important co-ordinating function. It makes it easier for parties to adjust their actions when knowing that the other party follows a standard. Less details need to be discussed and the own actions can be adjusted in beforehand. Consequently, this can also reduce the amount of information that is needed. Another benefit from standards is simplification. They reduce the number of possibilities needed to be considered. Furthermore, what has been argued is that standardisation brings advantages in large scale production. This can especially be seen in standardisation of products. (Brunsson \& Jacobsson 2000) 


\section{Challenges with standardisation}

The main objectives against standards are that they are seen as unwelcome, unnecessary and that they are working against the freedom individuals and organisation have and the free market. Furthermore, standards can make it harder for parties to differentiate from each other, which is seen as very desirable in the business world. More standards have also been argued to cause a decrease in creativity and innovation. Additionally, it might be harder to develop and learn from each other. (Brunsson \& Jacobsson 2000)

There is also an argument about the standardisers. They set the rules, but others comply. The standard is depended on the trustworthiness of standardisers knowledge and goodwill. It also relies on if the standardisers know what is best for everyone that will follow the standard. In this view, it is commonly argued that a democratically elected body is more suited to determine the rules than a private organisation. (Brunsson \& Jacobsson 2000)

One big challenge with standardisation is to find a balance. If the standards that regulate the green bond markets are too strict, it can become too costly for the issuers and result in a slow market growth. It may also limit each parties' freedom in a negative way. A standard can on the other hand also be seen as too loose and weak, which instead leads to it not being sufficiently democratic or leading to undesired rules. However, it is important to ensure transparency, because this creates more confidence, which can expand the investor-base. If trust is misused and investors are misled even by only one issuer, the entire market could be affected and lose credibility. (Brunsson $\&$ Jacobsson 2000)

\section{EU Green Bond Standard}

This section will go through the EU Green Bond Standard. Starting with presenting the background of the standard, it will be followed by its establishing process and its aim.

\section{Background to the EU Green Bond Standard}

Climate and environmental-related challenges are becoming more and more important. As mentioned in section 2.1, the role of green finance in the economy has grown during the years. More resources are being put into it as it reflects stakeholders changed values. Even though green bonds play an important part when it comes to financing assets needed for a low-carbon transition, there is no unified standard for green bonds in EU. As a result, the need for one has been argued and is now in the establishment process. (European Commission b (n.d.)

\section{The European Green Deal}

The European Green Deal is a growth strategy by the European Commission for 2019-2024. It aims to transform the EU into a fair and prosperous society, with a modern, resource-efficient and competitive economy where there are no net emissions of green gases in 2050 and the economic growth is not connected to resource use. Furthermore, it also focuses on protecting, conserving and enhancing the natural capital EU has and to protect the citizen's health and wellbeing from impacts and risk related to the environment. This strategy is the Commission's commitment to tackle both climate and environmental-related challenges. (COM/2019/640 final) 
A roadmap of the key policies and measures needed in order to achieve the European Green Deal has been made. This roadmap includes actions like Action plan on financing sustainable growth, Integration of the Sustainable Development Goals in the European Semester and a comprehensive plan to increase the EU 2030 climate target to at least $50 \%$ and towards $55 \%$ in a responsible way. (COM/2019/640 final)

\section{Action Plan on Financing Sustainable Growth (Action Plan)}

The commission's High-Level Expert Group on sustainable finance recommended in their final report that a green bond standard should be established. As an effect, it was included in the Action plan on financing sustainable growth that the European Commission published in March 2018. This plan contains a comprehensive strategy on how to connect finance with sustainability. It includes ten key actions, which can be grouped into three categories. (European Commission 2020, European Commission b 2019)

The first category is Reorienting capital flow towards a more sustainable economy which consists of action 1 to action 5. Action 1 is the establishment of a clear and detailed EU Taxonomy, a classification system for sustainable activities and will act as a base for the EU GBS. Action 2 in the Action Plan consists of European Commissions commitment to create standards and labels for green financial products. (European Commission 2020)

Technical Expert Group on sustainable finance (TEG)

A Technical Expert Group on sustainable finance (TEG) was then set out in June 2018 by the European Commission. Their task was to assist in the development of a unified classification system for sustainable economic activities, an EU Green Bond Standard, benchmarks for low-carbon investment strategies and give guidance on improving corporate disclosure of climate-related information. The members of TEG are from different sectors, such as the civil society sector, the academia sector, the business sector and the finance sector. There are also 10 more members and observers from EU and international public bodies. (European Commission b 2019)

In March 2019 the TEG published its interim report on an EU Green Bond Standard with the aim to get feedback from the public. This report contained a draft of an EU Green Bond Standard. It provided a motivation for action, explained how the standard should be developed and implemented. Over 100 organisations gave feedback on the report and overall, the feedback was positive, and the organisations supported the establishment of a voluntary EU Green Bond Standard. (European Commission b 2019)

TEG studied the detailed feedback and created an improved version which was published in June 2019. It contained a report on EU Green Bond Standard together with a summary of its key recommendation. The report proposes that a voluntary EU Green Bond Standard should be made by the European Commission. This would enhance the effectiveness, transparency, comparability and credibility of the green bond market and on the same hand encourage actors on the market to issue and invest in EU green bonds. (European Commission b n.d.)

In March 2020 TEG publishes their usability guide for the Green Bond Standard. This guide is built on the recommendations of the June 2019 report and aims to help the market actors. It gives them guidance on the use of the proposed standards and the set-up of registration scheme for external verifiers that is markets based. It also contains an updated proposal on the EU Green Bond Standard. (European Commission b (n.d.) 
The European Commission have further on done two consolations. The first one is a public consultation on the renewed sustainable finance strategy, which took place from 6 April to 15 July 2020. The second one is a targeted consultation on the establishment of an EU Green Bond Standard. This one is built and consulted on the work of the TEG and took place from 12 June to 2 October 2020. Based on these two consultations outcome and ongoing bilateral stakeholder dialogues, a decision on how to go forward with the Green Bond Standard will be made by the European Commission. (European Commission b (n.d.)

\section{EU Taxonomy}

As mentioned in section 3.1.2., the action plan on financing sustainable growth's first action is to establish a clear and detailed EU Taxonomy. The EU Taxonomy can be defined as a classification system for sustainable activities and will act as a base for the EU GBS. It is the first system designed by a major regulator that sets out sustainability criteria for use in financial products. The taxonomy can be seen as a tool that aims to support investors, companies, issuers, and project promoters when navigating towards a low carbon, resistant and resource-efficient economy. It aims to provide clarity via a common language for its stakeholders and is seen as an important aspect in order to scale up sustainable investments and implementing the European Green Deal. (European Commission c n.d., TEG 2020)

The taxonomy will provide definitions on which economic activities can be seen as environmentally sustainable. This can be seen to enable security for investors, protect private investors from greenwashing, contribute companies with planning the transition, mitigate market fragmentation and as well assist relocating investments to where they are needed the most. The taxonomy has set out three performance thresholds, also referred to as technical screening criteria, for economic activities:

Substantially contribute. At least make one substantial contribution to one of six environmental objects, which can be seen below:

1. Climate change mitigation

2. Climate change adaptation

3. Sustainable and protection of water and marine resources

4. Transition to a circular economy

5. Pollution presentation and control

6. Protection and restoration of biodiversity and ecosystems

Do no significant harm. Do no significant harm to the other five (or less if less are relevant) environmental objectives.

Minimum safeguard. Minimum safeguards should be met. For example, OECD Guidelines on Multinational Enterprises and the UN Guiding Principles on Business and Human Rights. 
The first set of criteria will be transposed into national legislation by the end of 2021. These include activities that contribute substantially to the mitigation and adaption of climate change. The taxonomy's thresholds for CO2emissions will then be used for classifying investments and disclosing the extent to which the investments are environmentally sustainable (KPMG n.d). (European Commission 2020)

\section{The proposed draft of EU GBS}

TEGs (2019) interim report includes a draft of a proposal of the EU GBS. It is built on market best practise, such as the GBP. It is divided into four sections: (1) Scope, (2) Objective, (3) Definition and (3) Guidance on the Components.

The two first sections contain essential information in a short and concise format. The first section states that the standard is voluntary and built on market practice such as the GBP. The second section contains the standards aim: to enhance transparency, integrity, consistency and comparability of EU Green Bonds and as a result increase the flow of finance to green and sustainable projects. (TEG 2019)

The third section presents the definition of an EU Green Bond, which according to the draft is "any type of listed or unlisted bond or capital market debt instrument issued by a European or international issuer that is aligned with the EU GBS". This is followed by requirements that all need to be met. Firstly, the alignment of the EU Green Bond with the EU GBS shall be confirmed in the issuer's Green Bond Framework. Secondly, the proceeds from the green bond or an equal amount to the proceeds, shall only be used in financing or refinancing either in part or full new or existing green bond projects, which are defined under the fourth section. Thirdly, an accredited external reviewer shall verify the alignment of the bond with the EU GBS. This shall be done in accordance with what is stated regarding verification in section 4. (TEG 2019)

The fourth section consist of the four core components: Green Projects, Green Bond Framework, Allocation and Impact reporting and Verification. The standard clarifies the four core components at the same time as it gives guidance of how to approach the requirements.

\section{Green Projects}

Guidance on the green projects is provided through a detailed interpretation of the EU Taxonomy, as the EU GBS are required to be aligned to the taxonomy and the taxonomy defines what is green. Some of the Technical Screening Criteria for the environmental objectives, sectors and economic activities will be quantitative, while other will be qualitative and principle based. As a result, a degree of interpretation is assumed to be needed for the market participants in order to apply the taxonomy when aligning to the EU GBS. During the time when the taxonomy and Technical Screening Criteria are not completed, issuers and external verifiers shall look to the fundamentals of the EU Taxonomy when verifying the alignment. The issuer and external verifier may turn to the fundamentals also in specific cases when the Technical Screening Criteria are not directly applicable by the issuer. Specific cases may be because of the innovative nature, the complexity and/or the location of the green project. It is emphasized that the flexibility that the exception "specific cases" allows for shall be interpreted narrowly and only where there are genuine issues with the Technical Screening Criteria application. (TEG 2019) 
Further on, the EU GBS will define more clearly which green assets and green expenditures a green project can include. The assets and expenditures should contribute to improve and maintain the value of such a green asset. Green assets can include physical assets and financial assets, such as a loan. The assets can be either tangible or intangible and may include a share of working capital that reasonable may be attributed to their operation. Green expenditures can include any capital expenditures and selected operating expenditures, for example research and development costs and maintenance costs that relates to green assets which either prolong the lifetime of the asset or increase the value of the asset. Operating expenditures like purchasing cost and leasing costs do not count as eligible except in specific and/or exceptional cases that are either identified in the taxonomy or given in future related guidance. For sovereigns and sub-sovereigns, green expenditures may as well include relevant public investments and public subsidies. Additionally, green assets that follow the mentioned eligibility criteria at issuance shall qualify without a specific look-back period. Eligible green operating expenditures on the other hand, shall qualify for refinancing with a maximum of three years look-back period before the issuance year. (TEG 2019)

The biggest difference from the GBP and existing market practises is that in the EU GBS Green Projects needs to be aligned to the EU Taxonomy where there are strict requirements on what counts as a green. Earlier the definition of a green project has not been as clear, and the issuers have been able to interpret more widely. The EU GBS will widen the scope of allowable use of proceeds for the issuers.

\section{Green Bond Framework}

The EU GBS requires issuers to provide a green bond framework (GBF). Earlier there has not been unified practise on green bond frameworks. Therefore, the EU GBS expands and formalises what needs to be included in order to make it a comprehensive and informative document for the investors and other market participants. The draft standard predicts the use of proceeds to be included in the legal documentation and requires the following areas to be included:

1. The Environmental Objectives of the EU Green Bond and how the issuer's strategy aligns with such objectives, as well as their rationale for issuing.

2. The process by which the issuer determines how green projects are in line with the EU Taxonomy, and, if applicable, qualitative, or quantitative Technical Screening Criteria.

3. A description of the green projects to be financed or refinanced by the EU Green Bond. In cases where the Green Projects are not identified at the date of issuance, the issuer shall describe where available the type, sectors and environmental objectives of the potential green projects.

4. The process for linking the issuer's lending or investment operations for green projects to the EU Green Bond issued. The issuer shall track the amount allocated to green projects in an appropriate manner and documented through a formal internal process, until such amount equals the net proceeds. 
5. Information on the methodology and assumptions to be used for the calculation of key impact metrics (i) as may be described in the EU Taxonomy, where feasible; and (ii) any other additional impact metrics the issuer will define.

6. A description of the Reporting (such as envisaged frequency, content, metrics).

The issuer can use a GBF that includes other products and frameworks, but then it has to be clear when the EUGBS is applied in the framework. Subsequential changes to the EU Taxonomy will not apply to already outstanding EU Green Bonds. In other words the EU Green Bonds will be grandfathered. Hence new issues shall be aligned with the newest version of the taxonomy. (TEG 2019)

\section{Reporting}

When it comes to reporting, the EU BGS requires two types of reporting: allocation reporting and impact reporting. The following elements shall be included in the reports:

\section{Allocation reporting:}

1. A statement of alignment with the EU-GBS.

2. A breakdown of allocated amounts to Green Projects at least on sector level, however more detailed reporting is encouraged.

3. The regional distribution of Green Projects (recommended on country level).

\section{Impact reporting:}

1. A description of the Green Projects.

2. The Environmental Objective pursued with the Green Projects.

3. A breakdown of Green Projects by the nature of what is being financed (assets, capital expenditures, operating expenditures, etc.)

4. The share of financing.

5. Information and, when possible, metrics about the projects' environmental impacts, which needs to be in line with the commitment and methodology described in the Issuer's GBF.

6. If it has not been already detailed in the GBF, information on the methodology and assumptions used to evaluate the Green Projects impacts.

Both reports can be done either on a project-by project basis or on a portfolio basis. The reports shall be published on the issuer's website or other comparable communication channel. The allocation report and the impact report shall 
together with the Green Bond Framework remain available until maturity unless it needs to be replaced by an updated version. (TEG 2019)

The current market practises on reporting are to report on the allocation of the funds to the green projects regularly, at least annually until full allocation. Impact reporting is not required, but some issuers do provide it. Consequently, the EU GBS has based the reporting requirements on the existing market practises, but they have become mandatory, and the requirements have been specified. (TEG 2019)

\section{Verification}

The EU GBS will require external verification. Both pre-issuance verification, which relates to the GBF, and postissuance verification, focusing on the alignment of the actual use of the proceeds with the GBP, the use of funds and the taxonomy, will be mandatory. However, no verification of estimated impact reports is required. The verification will be provided by accredited external verifiers. In order for external verifiers to get the accreditation, they will have to comply to high-level criteria such as code of conduct, professional qualification and the application of standard procedures. The external verification shall be available on the issuer's website or other comparable communication channel. The pre-issuance verification shall be published before or at the time of the issuance of the EU Green Bond. The post-issuance verification can be published either together with the final allocation report or within one year. The current market practices have not required any verification or specific accreditation of the external verifiers. (TEG 2019)

\section{Implementation}

In TEGs (2019) interim report a recommendation on the implementation has been set out. TEG has proposed that the EC adopt a voluntary recommendation of requirements for issuers, intermediaries or other third parties that are a part of the issuance or verification process. The recommendation is suggested to be done in form of a communication or another kind of EU act that is voluntary and non-binding. The proposed draft of the EU GBS that is included in TEGs interim report would then be finalised and included in the recommendation. In order to make the implementation successful, the TEG recommends the EC to implement incentives in order to support the adoption of the EU GBS. Potential incentives, such as different encouragement to stakeholders and tax incentives, are discussed in the interim report. Also UNEP et. al. (2016) argue that incentives are important to introduce to be able to decrease the cost of capital for green project, increase investor certainty and catalyse investment capital into green investments.

Furthermore, the rate of adoption in the market and the impact of the EU GBS is recommended by TEG (2019) to be monitored. The Sustainable Platform has been mentioned as an example for the monitoring. The standard is recommended to be evaluated after three years in order to see how the goals have been met. Special focus should lay on whether promoting market transparency and integrity has increased the market size as a result of more financial flows channelled to climate change mitigation and environmental objectives. After the evaluation has been done, it is further suggested that EC consider suitable measures needed to support the implementation. Mentioned as a possible measure is a recourse to legislation. 


\section{Underlaying principles and aims with the standard}

According to TEG (2019) the EU GBS should be (1) a voluntary standard, (2) built on market best practice, (3) it should be both a European and international standard and (4) it should be open to existing green bond transactions and to all type of issuers. Furthermore, the standard is expected to contribute to the EU's sustainable finance policy objective, promote market integrity and support market growth and tracking of financing flows.

The standard also aims to address the barriers to the development of the green bond market mentioned in section 3.2.2.1. As the EU GBS is being built on the proposed EU Taxonomy, it will clarify the green projects and expenditures at the same time as it aims to expand the eligible green projects and expenditures. Furthermore, through the alignment with the EU Taxonomy, it will as well clarify green definitions and address reputational risk. This is something that KPMG (2019) also see as positive outcomes with the standard, as it will provide a clear and defined protocol for issuing green bonds. (TEG 2019)

Both TEG (2019) and KPMG (2019) also see improvements regarding the varying quality and extent of external reviews. As the EU GBS aims to clarify and standardise the external review procedures, reputational risk will further mitigate and ease the market concerns regarding greenwashing. TEG (2019) argues that when standardising, the verification process, duplications of effort can be avoided and therefore costs of external reviewers can be reduced. The whole reporting requirements will also be streamlined and hence the reporting can be simplified by distinguishing between allocation reporting an impact reporting.

With the establishment of EU GBS, KPMG (2019) are also expecting investors interest in this asset class to increase, which in turn will expand and strengthen the green bond market. This can be argued because of green bonds becoming more credible and easier to report on. Another outcome that is seen with the standard is the opportunity to issue more robust green bonds, thanks to the standard being stricter than other standards. Further, EU GBS gives issuers the opportunity to launch taxonomy-aligned green bonds at a cost of capital that potentially would be lower. This is of interest as taxonomy-aligned green bonds can strengthen companies Environmental, Social and Governance (ESG) related targets and climate commitment. Which will provide compelling data to the ESG reporting and is therefore favourable for both investors and financiers.

Lastly, KPMG (2019) also points out that implementing EU GBS will cause extra work. However, the positive aspects with the EU GBS are seen as bigger. By improving the reporting, issuers reputation is seen to be enhanced. As well, the investors taxonomy-aligned investments and ESG reporting can be benefitted. As a result, the financing of green and sustainable projects is expected increase.

\section{Potential incentives}

It has been emphasised that in order to make a standard work, incentives are needed to be in place. TEG (2019) has included potential incentives to support the EU Green Bond Standard in their final report on the EU GBS. These incentives are meant to contribute to the green bond issuers and the development of the green bond market. Further on, they are meant only for bonds complying with the EU GBS requirements. The incentives have been divided into 
two main categories: (1) incentives that could be implemented in the short-term and (2) incentives that could be more complex to implement.

Incentives that could be implemented in the short-term

These incentives are seen to be able to implement in the short-term and in a cost-effective manner.

Encourage investors to increase their holdings in EU Green Bonds. Investors, especially European institutional investors, are seen to play an important part in the development and promotion of best practices and standards. Therefore, if investors would use requirements of the EU GBS in their fixed-income investment strategy and portfolios, incentives would be created. Also, by having a clear and active dialogue with green bond issuers and underwriters, this could be strengthened even more.

Disclosure of EU Green Bond Holdings by European institutional investors. It has been seen that increasing transparency can have a significant impact on increasing the demand and growth in the European green bond market. Hence, requiring more disclosures may have positive outcomes.

Encourage Central Banks / Supervisors to lead by example of scale up green finance. Central banks and supervisors are seen to have a strong role in the green finance market. Therefore, by emphasising and implementing a preference for EU green bonds when investing in green bonds, the greening of the financial system would be promoted and incentives for issuing EU green bonds would occur.

Encourage banks to find ways to enhance pricing of green assets. Some financial institutions have voluntarily started to apply positive factors when they provide loans that finance green assets. This positive factor could be giving a better price, which would trigger higher demand of green financing instruments.

Provide financial incentives to support the EU Green Bond Market. By developing short-term and long-term financial incentives, the green bond markets development can be supported. This can either be done by for example the European Commission or public institutions in the EU member states.

Encourage EU public and private sector bond issuers to adopt the EU-GBS. Both the public and the private sector play an important part when it comes to developing the market. Therefore, their promotion and support of the implementation of the standard is seen as valuable.

Use the requirements of the EU-GBS as technical criteria for future EU ecolabel for financial products. An EU Ecolabel for financial products is currently being established. The EU GBS can be made as a technical criteria for the label and hence the standard can become more desirable to align to.

Incentives that could be more complex to implement

These incentives are seen as more complex to implement as they require agreement from other authorities, different competencies or would require more time for the implementation. Additionally, these incentives are not limited to green bonds, they are seen to be able to enhance green investments at large.

Tax incentives. Tax incentives for EU green bond are seen to be able to support future growth in the market. Tax incentives could either be granted at issuer or investor level. Similar cases when tax incentives in the fixed income 
market have been implemented can be seen in the in the area of clean energy, where the US tax-code allows accelerated depreciation for companies.

Financial sector regulation and prudential rules. If central banks and supervisors would assess risk profile differently for green financing and non-green financing, incentives would be created. Some banks have already started to price mortgages aimed for energy-efficient property at a lower rate, which means that a lower risk premium can be seen.

\section{Previous Research}

This section will discuss relevant previous research about adopting new standards. Previous research regarding adoption of standards is mainly on IFRS and IAS. This means that most of the studies are older. Additionally, previous research tends to focus on the standards' effects after the adoption. As this section examines a standard during its establishment and the thoughts of specific stakeholders, there is not much similar previous research to be found. Furthermore, as this research focuses on the issuers' thoughts about the standard and not on green bonds in particular, previous research about green bonds have not been included in this section.

\section{Benefits with adopting standards}

Mazhindu and Mafuba (2013) studied the level of adoption of IFRS for small to medium enterprises in Zimbabwe. They used a combination of two qualitative methods, questioners, and interviews, to conduct their research and had a sample of 30 responses from small to medium enterprises (SME), Small Enterprise and Development Corporation, Ministry and professional bodies. Their results showed that there were a number of benefits for small to medium enterprises that adopted IFRS. Comparability of financial statements was ensured, investor confidence was built and the increased accountability allowed for growth.

However, even though Mazhindu and Mafuba (2013) could see increased accountability, Behnma \& McgLean (2011) have concluded that improved accountability is not ensured when adopting standards. They studied the accountability of IAS by using a neo-institutional lens in order to show which type of standards are more likely to be decoupled from daily core business practices of an organisation. They divided the IAS into three different categories, principle-based standards, certification-based standards, and reporting-based standards. The analysis showed that when IAS are clearly defined, have a high cost of adoption, require evidence of compliance and levy significant sanctions for non-compliance, they are likely to be more fully integrated into companies' daily operations than those with unclear expectations, low cost of adoption, and a lack of sanctions and assurance mechanisms. When it comes to the different standards, certification-based standards are less likely to decouple from a business' day-today core practises than principle-based standards and reporting based standards. Reporting-based standards may not include sanction mechanisms for non-compliance which may lead to a lack of comparability of the reports and hence also to a lack of accountability. This means that the adoption of standards does not necessary lead to greater accountability.

Furthermore, Barth, Landsman and Lang (2006) have also studied the IAS. They looked into whether there is a positive relationship between applying IAS and higher accounting quality. The study used a regression method and 
a data sample consisting of 319 firms that adopted IAS between 1994 and 2003. The data is collected from year 1990 in order to include the pre-adoption period data as well. Results show that firms that apply IAS experience higher accounting quality than they did when only applying domestic generally accepted accounting principles (GAAP). This means that an improvement in accounting quality is associated with applying the International Accounting Standards.

Karamanou and Nishiotis (2005) examined the valuation effect of firm voluntary adoption of International Accounting Standards (IAS) by using an event study procedure and a cross-sectional variation analysis. The data sample consisted of 56 non-US firms that voluntarily used IAS for financial reporting purposes between 1989 and 1999. The announcement dates were matched with financial data from DataStream international. The results showed that there is a positive effect of IAS adoption on the firm value. Furthermore, there are strong positive abnormal returns at the announcement of the IAS adoption and as well a long-term reduction in the cost of capital. Additionally, the study showed a significant increase in the number of analysts issuing recommendations and as well a significant upgrade in the recommendations after the IAS adoption. Furthermore, Barth, Landsman and Lang (2006) found a weak relationship between applying IAS and a lower equity cost of capital.

Armstrong et al (2008) examined the stock market reaction associated with the adoption of International Financial Reporting Standards (IFRS) in 2005 in Europe using cross-sectional analyses. This study examines European firms through an event-study using data collected between 2002 and 2005 from DataStream through Thomson One Banker Analytic. The results show that for firms with lower quality pre-adoption information, there is a positive market reaction. On the other hand, there is a less positive reaction for firms domiciled in code law countries.

Armstrong et al (2008) also found that there is an overall positive reaction to the adoption of the IFRS standards, especially for firms that have high quality preadoption information. This is because investors expect net convergence benefits from the adoption of IFRS. Their findings also show that investors in the European firms anticipated net benefits in association with the adoption of the new standards.

Jakubik and Uguz (2020) investigated if the adoption of green bond policies by European insurance companies has a positive impact on companies' equity prices. This was done through a pooled estimate model with clusterrobust standard errors. The sample consisted of 15 insurers in Europe and their market data from 2012 to 2019. They could not confirm a positive effect on the equity price when introducing green bond policies. They did however find that when it comes to issuance of green bonds and launching of green funds green policies have a positive pricing.

\section{Challenges with adopting standards}

Wong (2004) studied the challenges in implementing the international standards IFRS and ISA. This was done through a combination of focus groups, interviews and written response from people who developed the standards, people who use the standards and people who rely on work performance based on the standards. Potential challenges with adoption and implementation that were discussed were issues of incentives, issues of regulation, issues of culture, issues of scale, issues of understandability, issues of translation, issues of education. Overall, the participants were positive about the implementation of the standard. IASB and IAASB were also seen as appropriate bodies for the development of the standards. The challenges that could be identified were, understanding the meaning of 
international convergence, translation of the international standards, complexity and structure of the international standards, frequency, volume and complexity of changes to the international standards, challenges for small- and medium-sized entities and accounting firms, potential knowledge shortfall and implications of endorsement of IFRS. Wong (2004) claims that there are benefits with standards, but they can only fully be realised when the challenges have been addressed.

When studying IFRS adoption on small to medium enterprises in Zimbabwe Mazhindu and Mafuba (2013) also noticed challenges. The main challenge was lack of awareness, as most of the people in the SMEs did not have the required knowledge about IFRS nor the level of qualifications needed. Another challenge that was brought up was lack of capacity, as many companies did not have proper accounting systems or records because of lacking accounting knowledge and cost of hiring professional accountants. Additionally, lack of separation between ownership and management was identified as a challenge, as SMEs directors may have less expertise in business and management.

Vigneau, Humphreys and Moon (2014) examined processes and consequences of adopting the Global Reporting Initiative on multinational corporation's corporate social responsibility (CSR). The research is based on an in-dept case study with data collected from 2011 to 2013 using four sources of information: semi-structured interviews, digitally recorded longitudinal observations of internal CSR committee meetings, documentation from multinational corporations and documentation from the GRI. Their results showed that substantive standard adoption can have unintended consequences on firms CSR management practices. They pointed out that specially the management structure and CSR committee function can be influenced. It is further emphasised that there is a need to look at the relationship dynamics between standards, as there might be a lack of it. The research show that the view of standard compliance has moved from either to adopt the standard, and use reporting as an organisational learning tool, or to not adopt the standard and decouple of policy and practice to instead provide a more nuanced view on adopting standards. Finally, the need for better coordination between different sustainability standards has been pointed out. Better coordination would increase the standard's potential to improve corporate accountability.

\section{Adoption of standards}

Aravind and Christmann (2011) have studied whether the quality of ISO 14001 implementation affects facilities environmental performance. This was done through ordinary least squares regression analysis and T-tests with crosssectional data from multiple sources, such as questionnaire survey and secondary data from several databases. The data sample consisted of 72 ISO 14001 certified facilities with 72 matched non-certified facilities in the United States. Their results showed that the implementation quality does affect certified facilities' environmental performance. When the quality of standard implementation is low, both the improvement of environmental performance and the signalising of good environmental responsibility will be weakened.

Mazhindu and Mafuba (2013) concluded in their research on the adoption of international financial reporting standards for small to medium enterprises in Zimbabwe that the adoption of the standard depended on whether companies maintained accounting records. The study showed that $80 \%$ of the SMEs did not maintain any accounting records and had not adopted IFRS. The remaining $20 \%$ of the SMEs that maintained accounting records complied 
with provision of IFRS for SMEs. Reasons for the low adoption was due to a lack of basic accounting financial knowledge and low level of encourage from policy makers within the retail trade sector.

\section{Overview of previous research}

Previous literature shows that adopting new standards entails both advantages and challenges. An advantage that has been mentioned in previous research is an increase of accounting quality, which has been explained due to increased comparability and to some extent increased accountability. There have also been positive outcomes when it comes to companies' reputation, for example gained investor confidence and a higher number as well as better recommendations by analysts. Additionally, positive financial outcomes have been identified, such as a lower equity cost of capital and a higher firm value. Overall, there seems to be a positive market reaction when standards are adopted. When it comes to adoption of green bond policies, no positive effect on the equity price has been found, but positive pricing has been seen in connection to issuance of green bonds and launching of green funds' green policies.

Challenges that have been brought up relate to a large extent to a lack of either knowledge or resources. It has been emphasised in the literature that understanding the meaning of standards can be very challenging, and there might be problems with having the required knowledge as well as the capacity of implement it. Especially when it comes to small- and medium-sized firms, the complexity that standards bring might cause issues. Additionally, it has been mentioned that the translation of standards can cause problems and that the implementation can have unintended consequences on firms' CSR management practices, which the company needs to be aware of. When it comes to sustainability standards, better coordination between the standards has been seen as crucial.

Low adoption has been argued to depend on a lack of basic accounting financial knowledge and a low level of encourage from policy makers within the retail trade sector. When adopting a standard, the implementation quality has been shown to affect certified facilities' environmental performance. Low implementation quality results in weakened improvement of environmental performance and lower signalising of good environmental responsibility.

\section{Methodology}

This section will introduce and explain the research methodology used in this study. A qualitative research method has been used in order to answer the research question. This section will explain how the data was gathered, how the research process was formed and how it has been analysed. The objective of this section is to present this, ensuring that the data collection progress has been conducted in a reliable and valid way guaranteeing a high-quality result.

\section{Research philosophy}

According to Ponterotto (2005) research philosophy refers to how a research has been conducted. Patton (2015) points out that there are two philosophies that dominate the literature within the research process, positivism, and phenomenology. This section will base its research process on the phenomenology philosophy, as this supports the aim of the study. The phenomenological perspective follows the lead of Deutsche and has its roots in philosophy and sociology. The phenomenological approach takes on the understanding of a social phenomenon through actor's own 
perspective. The focus is on examining how the world is experienced and the importance lays in how people perceive it.

\section{Research design}

The purpose of this section is to investigate green bond issuers' views about the upcoming the EU Green Bond Standard. Previous research that has studied implementation of new standards has generally examined the standard's effect after its implementation. Then quantitative data has then been available, and a quantitative method has been used. This study will instead investigate the green bond issuers' thoughts on the new possible standard before it is established. As the EU Green Bond Standard still is in progress, there is no quantitative data available on the green bond issuers' thoughts about the standard. Therefore, a qualitative method will be used.

Qualitative research is suitable in this section because it puts more emphasis on words than numbers. As we would like to know the issuers' thoughts, qualitative research is the most relevant method. Furthermore, it has an inductive view of the relationship between theory and research, which means that theory is generated from the research, and not vice versa as it is with quantitative research. Therefore, it is suitable for areas and subject with little data and previous research. (Bryman 2012).

Qualitative research has an epistemological position, which can be described as interpretivist. This means that instead of adopting a scientific model as in quantitative research, qualitative research focuses on understanding the social world through examining the interpretation of participants of that world. This supports the choice of method, as the objective of this study is to establish green bond issuers' views on the EU Green Bond Standard. (Bryman 2012)

The empirical data for this study has been gathered through qualitative semi-structured interviews. While qualitative research has been done, open-ended interviews have been used in order to let the participants speak freely, instead of choosing from standardised answers. The interviews were conducted one-on-e to obtain the individuals' non-biased, individual viewpoints. When gathering participants for example focus groups, there is always a risk that some of the participants' opinions will not be heard because of a lack of courage to express their opinions in a group. Stronger personalities may dominate the discussion and unpopular opinions may be harder for the participants to share. Furthermore, when the participants hear each other's opinions, the individual viewpoint may change. This in turn may lead to participants agreeing to the majority's standpoint, resulting in fewer varying answers. Therefore, one-on-one interviews has been choice as the most suitable method for this study. (Patton 2015).

All the interviews have been conducted through video calling instead of in-person interviews. This is partly because of the Covid-19 pandemic that was ongoing when the interviews took place, however the method is also suitable due to the wide geographical spread of the participants. Video calling makes it possible to reach all the participants. The method also saves time for both the researcher and the participants (Krouwel, Jolly \& Greenfield 2019). Considering that the majority of the participants of the interviews hold a high position within their respective company, this is an advantage. Furthermore, research has shown that there is a difference between in-person interviews and video calling, where in-person interviews are marginally superior. As the difference is sufficiently 
modest, the time and budget benefits justify the use of video calling (Jenner and Myers 2018, Krouwel, Jolly \& Greenfield 2019).

\section{Sample}

The data has been obtained through interviews conducted in November and December 2020. The data sample consists of nine interviews. An overview of the sample can be found in figure 3. The aim of the study is to gather opinions from green bond issuers regarding the EU Green Bond Standard. In order to get information on an in-dept level, a qualitative method has been used and the focus has been to gather a few information-rich cases. The participants are employees in Nordic companies and organisations working with issuing green bonds. The participants have been chosen through criterion-based sampling, which is further explained in sub section 5.3.1.1.

According to Bryman (2012) it is impossible to know the required sample size before the theoretical saturation has been achieved. Therefore, no sample size was set beforehand. Instead, as long as there were new inputs gattered, more data was collected. When new interviews no longer were seen to bring added value a perceived sense of saturation was reached. What can be noted is that there is a limited number of green bond issuers in the Nordics and that participation in this study is voluntary. This made the possible number of participators relatively small.

This section studies the EU Green Bond Standard, whereby it is logical to narrow the participants down to only green bond issuers in the EU countries. I have chosen to narrow it down further and only look at the Nordic countries. This is due to the Nordic countries being known as frontrunners in environmental regulation, societal awareness and behaviour changes consistent with a sustainable economy since the 1970s (McCormick, Richter \& Pantzar 2015). Furthermore, the Nordic countries are seen as pioneers when it comes to using green bonds to accumulate capital for sustainable goals (Nassiry 2018). Additionally, a co-operation between both the countries exist, which can be seen in for example the work of the Nordic council, but specially between the Nordic green bond issuers. The Nordic Public Sector Issuers (2020) has stated in their Position Paper on Green Bonds Impact Reporting 2020 that a common Nordic position to the issues can be beneficial to other issuers. They also emphasise that everyone benefits from sharing experiences and know-how.

Nordic actors are also in the forefront when it comes to promoting market integrity. According to external reviews they are demonstrating best practice, Nordic actors are pushing investor standards and they are seen as leading in the international dialogue. (CBI 2018) 


\begin{tabular}{llll}
\hline Code & Duration (hh:mm) & Location & Date \\
\hline A & $00: 26$ & Video call & 20.11 .2020 \\
B & $00: 24$ & Video call & 24.11 .2020 \\
C & $00: 42$ & Video call & 25.11 .2020 \\
D & $00: 44$ & Video call & 26.11 .2020 \\
E & $00: 29$ & Video call & 26.11 .2020 \\
F & $00: 23$ & Video call & 2.12 .2020 \\
G & $00: 25$ & Video call & 8.12 .2020 \\
H & $00: 24$ & Video call & 17.12 .2020 \\
I & $00: 27$ & Video call & 18.12 .2020 \\
\hline
\end{tabular}

Figure 4. Overview of the sample

Purposive sampling

Through purposive sampling, information-rich cases are selected. Information-rich cases can be described as cases which one can learn a great deal about the issues that are of central importance to the purpose of the inquiry. This means that when gathering samples, in our case conducting the interviews, the participants have been chosen in a strategic way to make sure that the sample is relevant for the study. Within the suitable sample, it is preferable that there is some kind of variation among participants, so that the sample members have different key characteristics relevant to the study. Within purposive sampling, there are several different strategies. This section will use criterionbased sampling. (Patton 2015)

\section{Criterion-based sampling}

Criterion-based sampling requires certain predetermined important criteria to be met to fit the purpose of the study. This is done to ensure that the participants have the required knowledge about the subject. This sampling method has been chosen in order ensure that the participants are well familiar and have pre-defined background with the issuance of green bonds and the upcoming EU Green Bond Standard. If these criteria are not met, the interviews would not be informationrich, which would lower the quality of the research and make the results misleading. (Patton 2015)

The criteria that needed to be met were:

1. Nordic actors 
The first criterion is set out in order to make sure that the participants are part of the area that is investigated in this study.

2. Individuals working with issuing green bonds

The second criterion is set out to ensure that the participants are information-rich and relevant for the research. They possess the knowledge needed about the issuing of green bonds and what might be affected by an EU Green Bond Standard. Furthermore, this section only looks into the issuers' thoughts, not the thoughts of other actors on the green bond market. It is also not enough for the participants to work at a company or within an organisation that issues green bonds, they need to work with green bond issuing themselves. In other words, the EU Green Bond Standard should affect their work.

\section{Interview guide}

This section uses semi-structured interviews. In order to support the interview process, an interview guide was made and used as a tool for the empirical part of the study. When conducting a semi-structured interview, the interviewer has some freedom in the interview. The interview guide provides a list of questions or issues that should be asked during the interview. This is done in order to ensure that the same base is used for all of the interviews and a similar use of language and phrasing is being used. However, the interviewer has the freedom not to follow the exact outlined schedule. Throughout the interview additional issues may be raised by the interviewer and discussed. These additional issues are an essential part of the study's outcome. Therefore, it is important that the questions are open-ended and that the nature of the interview allows an interactive process of explanation. Issues that previous interviewer have brought to light can also be discussed. This is seen as a flexible process which puts emphasise on the interviewees understanding on the issues and events. (Bryman 2012, Patton 2015)

The questions were formed in order to get the answer of green bond issuers' thoughts about the possible EU Green Bond Standard. They had been developed from theory within the subject and previous research on adapting standards. The interview guide has been set up according to Patton's (2015) recommendations. Patton argues that the first questions should be simple and clear so that the participants get comfortable in the interview situation. Therefore, the interview starts with background questions about the participant and the company. These questions also verify the selection-criteria mentioned in section 5.3.1.1. The interview guide is not structured according to different themes. This is because thematic coding will be used to analyse the results and their codes and themes should be found from the content (Braun and Clarke 2012). An order has however been created to make the interview and questions flow easier. The questions have been formulated so that they are not too specific nor leading and in order to support a good interactive and non-biased interview.

\section{Data analysis}

The data in this section has been analysed through thematic coding, which is a type of qualitative data analysis. Thematic coding is a method where the researcher systematically identifies and organises data. This method focuses 
on finding patterns and meaning across data sets, in other words finding collective or shared meanings and experiences. The method is suitable as this study looks into Nordic issuers' views on the EU Green Bond Standard and thematic coding focuses on the experiences and meanings that are reported in the data. (Braun \& Clarke 2012).

Thematic coding is an accessible and flexible method of qualitative data analysis. It allows the researcher to identify the patterns of meaning. Numerous patterns can be identified across a data set, which means that it is highly important that the researcher identifies the pattern that is relevant for the study. In this study, the data has been coded manually by going through the transcriptions of the interviews and picking up reoccurring subjects. The views on these subjects have in some cases been consistent and in other cases differed from each other. For a code to exist, the requirements in this study were that the code was mentioned by at least two participants. To ensure that all relevant codes were found, the data has been gone through several times. First, the researcher has conducted the interviews, whereafter the interviews have been transcribed. After that, the data has been analysed twice. First by underlining the codes on the transcript and thereafter by noting them in Microsoft Excel to get an overview and have them collected. (Braun \& Clarke 2012)

After the data was processed, the codes were grouped into themes according to the best fit and the patterns that were found through the coding. The differences between companies were often brought up in the data set, either as the code geographic location, section or size, this turned into the theme Company Structure. The next theme Market Barriers grouped together codes linked to challenges that were mentioned as market barriers in the interviews and did not relate to the company structure. The rest of the codes were either connected with the implementation or the standard's impact. This resulted in the development of the themes Implementation and Impact.

Thematic coding gives the researcher the possibility to focus on the data in several different ways, which makes it flexible. Data can both be legitimately analysed across the whole data set or one aspect of a phenomenon can be examined (Braun \& Clarke 2012). This section analyses the data across the whole data set. Furthermore, when reporting, the researcher can tell the data's obvious or semantic meaning as well the latent meanings, assumptions, and ideas behind what is stated can be investigated (Braun \& Clarke 2012). The data will first be presented in the next section, whereafter the following section will dive deeper into the meaning of the data and discuss it further.

\section{Research ethics}

When conducting qualitative studies, it is of major importance to keep research ethics in mind. Data is gathered as a primary source and people are directly involved in the process. Therefore, four aspects have been taken into consideration. Firstly, the participation is voluntary, and the participator needs to be ensured about it. Secondly, the participants comments and behaviour are confidential. Thirdly, the participants should be protected from any possible harm. Lastly, mutual trust needs to be ensured between the researcher and the people taking part in the study. All of these four aspects have been taken into consideration throughout the study. During the collection of data, these aspects have been emphasised both when contacting the participants and when conducting the interviews. (Silverman 2011). 


\section{Quality of research}

When conducting research, it is important to ensure its quality. Kirk and Miller (1986) argue that the objectivity of research can be evaluated through reliability and validity of the observations. These two concepts have been commonly used for quantitative research, but Kirk and Miller (1986) also argue that it is highly relevant for qualitative research.

Reliability can be explained as the extent to which a measurement procedure will give the same answer regardless of how it has been carried out (Kirk and Miller 1986). In other words, how similar the results of the research would be if another researcher would conduct the study. Kirk and Miller (1986) have divided reliability into three categories when it comes to qualitative research. The first one relates to what degree a measurement will remain the same when it is repeated. The second type refers to the stability of the measurement and the third type refers to the measurement's similarities within a certain time period. To ensure the reliability of this section, all the steps taken when conducting the research have been described. The interview guide with the questions asked can be found in the appendix. Consequently, another researcher can conclude the same research.

Validity can be defined as the extent to which the measurement procedure gives the correct answer (Kirk and Miller 1986). It can be divided into internal validity and external validity. Internal validity refers to whether the results of the research are true and external validity refers to whether the results can be generalised. The validity of the study has been ensured by recording the interviews in order to be able to go back to the data and verify the statements. If the interviews would not be recorded, there would be a risk related to the mishearing or misremembering by the researcher. Furthermore, anonymity was guaranteed for the respondents to reduce social desirability and increase the trustfulness of the responses (Podsakoff et al. 2003). (Ghauri and Gronhaug, 2010).

\section{Empirical findings}

This section will present the results from the empirical part of the study. The results will be divided according to the main themes from the data coding. The themes and codes can be found in Figure 5 below. The first theme Company structure relates to the company format and how that may have an effect when it comes to the EU GBS. The second theme Market Barriers consist of challenges seen as market barriers that may occur with the EU GBS. The third theme Implementation concerns aspects that might have an effect on the implementation of the standard. Lastly, the fourth theme Impact takes on the possible impacts that the standard may have. 


\begin{tabular}{llc}
\hline Themes & Code & Code \\
\hline Company structure & Geographic Location & GL \\
& Sector & SE \\
Market Barriers & Size & SI \\
& Reporting Costs & RC \\
& External Verification Costs & EC \\
& High Requirements & HR \\
Implementation & Lack of Incentives & LI \\
& Adoption Time & AT \\
Impact & Sustainable Reputation & SR \\
& Investor Requirements & IR \\
& Harmonising EU & HE \\
& Non-EU Green Bond & NGB \\
& Continuous Development & CD \\
\hline
\end{tabular}

Figure 5. Themes and codes in the data set

\section{Company structure}

What can be seen from the dataset is that the EU Green Bond Standard will affect companies differently depending on their structure. This is mainly seen because of where the company geographically is based, in which sector they are in and the size of the organisation.

Geographical location. Many of the interviewees argued that the geographical location affects due to that countries and regions are different. One EU wide definition might not be as suitable for all countries and it might favour some countries more than others. Interviewees tend to feel that there is a division between the Nordic countries and other parts of Europe and the world.

Several aspects are mentioned in the interviews as differences between the Nordic countries and other countries. Firstly, it is seen that the level of trust in the financial market is very strong in the Nordics. Investors trust the issuer even though issuers are not following a standard. This has been argued due to that the Nordic green bond issuers have been on the market for a longer time and they have established well working processes of high standards. They are frontrunners in the market with high quality green bonds and a good reputation. Nordic green bond issuers argue that the same kind of trust in the market might not be found in other countries and therefore there is a bigger need of standardisation elsewhere.

"We do operate in the Nordics, which is I would say the corner of the world where green bonds have developed the most... What we see is that the EU Green Bond Standard could perhaps help support the market in some Europe, but also the world perhaps. Where we see less of this trust expectations from the market, from investors and other stakeholders. We keep very high standards in our green bonds. So, from the Nordic perspective I wouldn't say that it adds that much quality to the market, but it really adds burden in terms of bureaucracy so if we only look at the Nordic context, it is a context I very much define by trust. That there is trust in our institutions." (C) 
Furthermore, the natural resources that the Nordic countries have differs from other countries. Some interviewees highlighted that the Nordics have great access to clean drinking water and a good level of energy efficiency and energy consultation. So, for the them, it does not make a lot of sense on spending resources on making the system more energy efficient or water efficient as these resources are abounded enough. The efforts should instead be prioritised into other areas where there are bigger room for improvements. In the existing green bond market this has not been a problem as issuers have been able to make their own priorities on the market and justify the greenness with their own arguments. The EU GBS will instead force all the issuers into an EU wide definition of what is green, which may not be as appropriate for all countries and might steer the green projects into areas that are not as important for some countries as for others.

"Then again as a Nordic player we again see the challenges in defining what is green on an EU wide level when we belong to a region that is in many ways so different from both the challenges and the solutions. That would suit continental Europe better. One example of that is there is a lot of talk about energy consolation or energy efficient which is of course very important objective. But as energy clean energy is more abounded in Norway than in the other countries." (C)

Further on, it has been brought up in interviews that the national laws and requirements might cause issues. Some sectors face challenges due to the set requirements by the taxonomy and the different countries own laws or requirements. As countries' legal systems are formed differently, this may cause issues as they do not cohere. For example, the requirements for green buildings are that a building needs to have a certificate A level. Different countries have different standards of certificate A level. This means that for example in the Nordics it will be very hard, or even seen as impossible, to reach that level, while in other countries the national law requirements for a building to get certificate A level is much lower. Therefore, some criteria are argued to be unfair because of the countries' differences.

"But we are quite worried about the taxonomy. Especially on the real estate area... It is quite hard to meet the criteria for a green asset in Sweden. I think the case is in Norway and Finland as well. And if you follow the Green Bond Standard you will have to align the Green Bond with the taxonomy. I think the hardest point is on the alignment with the taxonomy." (F)

As national laws may not be aligned to the standard, this might especially become an issue if this standard in the future should be used as an international standard. The standard is seen by several interviewees to have been created from a Euro-centric view, not have taken countries outside the EU into enough consideration even though it has been argued that this could also be used as an international standard. For countries outside of EU there might be even more challenges with the differences between the national laws and the requirements of the standard. For example, the technical screening criteria Do no significant harm in the taxonomy. As the EU Green Bond Standard will be aligned with the taxonomy, all EU Green Bond issuers need to comply with the taxonomy as well. The standard is built on EU legislation which means that it will not be consistent with non-member countries' laws. As a result, national laws might not be sufficient to rely on for the Do no significant harm criteria, as the criteria's might be stricter than the national laws.

"They (the European Commission) try to make a system that should work within the EU, within all of the member states. But I don't think that they have established a good taxonomy, given the differences between countries and regions and how far we reach within the whole EU when it comes to sustainability." (F) 
"And then we always have to remember that we should include everybody globally and this is EU so we can foresee that you know people outside of Europe region or EU, that they might have you know, they might struggle as well. For example, with do no significant harm feature because they are not using the EU laws and regulations." (I)

Furthermore, the standard is seen by Nordic green bond issuers to have been tailored by some of the bigger member countries and institutions and might not be suitable for all member countries or worldwide. The same concern is also applicable on the taxonomy, which is seen to be coloured by stronger actors and their interests. These interests have been argued to some extent have been weighted more heavily than the practical implications from users of these documents to some extent.

"And then you have EU Green Bond Standard that is obviously first a foremost an EU regional approach. The real value adds more is as I said there is a lot of structure and thoughts that has gone into the standard itself, but obviously the real gamechanger with that is the link to the taxonomy and again that has been shaped from a European perspective, predominate European institutions have been in the sort of discussions around the technical screening criteria." (G)

It is seen that the Nordics have come further in the development of the issuance of green bonds than other countries. A common view among the interviewees is that other countries in Europe and the rest of the world might have more use of the standard than the Nordic countries, while there is a bigger need of creating trust and comparability in other parts of the EU. The Nordics already see that they have a high standard of green bond issuance and therefore the need of the standard is not argued as important for them. Interviewee A states that while the Nordics have come far in the issuance of green bonds, it might be easier for the Nordics to adopt the standard for other countries. This is due to the already high standard of processes and knowledge. Many Nordic issuers already have strong processes that might not need a lot of improvements in order to be sufficient for issuing an EU green bond. The in-house knowledge is as well seen as high and therefore less additional resources may be needed if Nordic issuers choose to issue EU green bonds.

"Many countries have come different long in issuing of green bonds. The Nordics we have come very far. The threshold under the EU Taxonomy is easier for us to apply even though there are nationally based. It will still be little easier for us than other countries." (A)

Sector. There is seen to be a difference between sectors as well. Here the main concern from the Nordic green bond issuers is the alignment to the taxonomy. Firstly, there will be a difference between issuers portfolios. Issuers with a uniform portfolio that only finance one kind of green projects will face easier adoption than issuers who finance several different green projects. This is due to that there needs to be different documentation of alignment for different kinds of green projects. Secondly, the taxonomy will have stronger requirements than the market practices and demands more documentation. As documentation will have to be done for all different kinds of green projects, it means that the number of different sorts of green project issuers have in their portfolio will affect the issuance.

"I think that the issuers will try to adapt and for some it will be easier than for others, for example issuers that have a uniform portfolio for instant. Say a wind power company, or a hydropower company or some manufacturing company with only one product line that is in line with the taxonomy, for them it will be easier to adapt. Whereas for the issuers category that I belong to, that is bank and financial institutions, it is going to be quite tricky because we finance large or a wide spectrum of projects ... Which means that we need to understand and apply these quit detailed criteria from different projects. And of course, also then demonstrate the alignment." (C) 
Especially the technical screening criteria Do no significant harm in the EU Taxonomy is seen as hard for some sectors. For financial institutions, the green bonds' proceeds will go to their costumers' projects. Not only do they manage a number of different green projects, but they will also not be the ones who will carry out the project. This results in higher levels of administration and supervision as the customers will carry out the projects. Furthermore, there will be more work to make sure that all the projects are aligned to the taxonomy. This means that a more thorough process would need to be done, which is stressed as both difficult and costly.

"So that means that project level analyses would be required, and which may be very difficult and costly for us because we are a credit institution. And we are not directly the ones who are building the building. So, it is our customers who are building the building, so it can be quite difficult for us to implement these do no significant harm because the project construction processes, they are all owned by the costumer and not by us. So, it would be quit costly due diligence process to do this for each project." (D)

"It is an important topic (do no significant harm), and we are good to include it, but it is just the usability of it, we struggle a little bit in certain sectors, for example in the SMI (small medium industry) sector and municipalities. How are you actually going to be able to fulfil this and also verify it." (I)

Another challenge that is mentioned both from interviewee $\mathrm{C}$ and $\mathrm{D}$ is grandfathering, which is a problem for the issuers who use a portfolio approach when allocating the proceeds instead of a bond-by-bond approach. Grandfathering means that the bonds would be grandfathering for the rest of their life and that the EU Green bond status would remain until maturity. If the issuer has a bond-by-bond approach, this will not cause issues as the bond is financing specific projects. However, for issuers who use a portfolio approach, this does not appear to be explicitly applicable to the underlining assets, the project side. The issue here is argued to be the taxonomy again. If the taxonomy changes, which it has been said that it will do from year to year, the whole portfolio will have to be reassessed when using the portfolio approach.

"The grandfathering is not applicable then to the project side or the assets, so the green assets. And this is a problem. So, the current draft would only be useful to the issuers who have this bond-by-bond approach where they link bonds to specific projects back-to-back. So, there is a few issuers who do this. But then the majority of the issuers use a so-called portfolio approach which is different from the bond-by-bond approach.” (D)

Size. What can be seen in the data set is that the size of the issuer has a difference when it comes to the EU GBS. This will as well be discussed under other themes and codes. The overall view is that smaller issuers will have a harder time to issue EU green bonds than bigger issuers. This is mainly because of the high requirements and need of resources. Smaller issuers may not have the capacity to issue EU green bonds both when it comes to capital and human resources. The reward they would get from issuing an EU green bond may then be too little in order for them to be profitable.

"My concern is also for the wider market that corporates or smaller issuers that do not have the same luxury of having this strong mandate will choose to stay away from this market if it gets to converse and too costly to join it." (C)

Bigger actors on the other hand have more resources and may also have the knowledge needed in-house already. As alignment to the standard will require more resources, bigger issuers will have it easier. Furthermore, bigger actors are argued to have been more involved in the establishment process and have been able to impact the standard and make it more suitable for them. A greater pressure on bigger actors to issue EU green bonds can also be seen as 
stakeholders may expect them to be early on the market. Therefore, they might not have the same option to choose to issue.

"I think that they (bigger market actors) are already taking the lead. For instance, the EIB they are heavily involved in this process. It makes sense because they also have a lot of resources available because it takes a lot of resources to have the full picture and to have the in-depth on the understanding of." (E)

\section{Market Barriers}

What also was brought up by the Nordic green bond issuers, is that the EU Green Bond Standard might create market barriers. These barriers can be divided into three main categories: High Requirements (HR), Additional Costs (AD) and Lack of Initiatives (LI).

High requirements (HR). The EU Green Bond Standard will have higher requirements than the Green Bond Principle and the existing market practises. There are both more and stricter requirements of what will count as a green bond and the issuance process.

In particular the requirements from the EU Taxonomy are seen as challenging for the issuers. For example, as mentioned in section 6.1, the taxonomy requires that in order for a project to be called green it has to contribute substantially to specific environmental objects which can be found in section 3.2. The taxonomy also requires that apart from contributing substantially to at least one of them, the projects cannot do any significant harm to the others. This criterion will add a great deal of extra documentation in order to show the alignment to the EU GBS and the EU Taxonomy.

As the requirements are becoming stricter the amount of documentation will increase. Both an allocation report and an impact report need to be issued. Further, external verification needs to be issued both pre-issuance and postissuance. The external verification also requires certain accreditations. Higher requirements mean an increased workload for issuers and a need for more resources. Interviewees have pointed out that the higher requirements will most probably result in a market barrier while everyone will not be able to issue EU green bonds because of the lack of resources. It is seen as especially hard for small issuers or new issuers as smaller or new potential issuers will not have the resources in place to take on these kinds of requirements.

"My concern is also for the wider market that corporates or smaller issuers that do not have the same luxury of having this strong mandate. They will choose to stay away from this market if it gets to converse and too costly to join it." (C)

The higher requirements may also bring fear for the issuers of not being aligned enough. As the standard is still being established and includes requirements that are new for the actors, several interviewees highlight that issuers might not feel comfortable issuing an EU green bond. Some documentation might be missing or the requirements might be interpreted the wrong way. The uncertainty might then cause investors not to issue EU Green Bonds.

"I think that the fact that it's linking to the taxonomy it provides an indirect challenge and that people certainly have been commenting on the taxonomy being perhaps a bit too strict or difficult to work with." (G)

Additional Costs (C). Furthermore, the Nordic green bond issuers point out that more costs will be added in order to issue an EU Green Bond. Firstly, as there are more requirements for an EU green bond than a non-EU green bond, 
more resources need to be put on the issuance to make sure that the green bond is aligned to the standard. For example, the alignment to the taxonomy and the technical screening criteria will require extra resources and will cause additional costs for issuers.

Secondly, as mentioned above allocation reporting and impact reporting will be mandatory when issuing EU green bonds. Both reports have certain requirements that need to be included. The current market practise requires an allocation report to be available, but impact reporting is only a recommendation. As the reporting increases, so will the costs of issuance. Currently, external reviews have also only been a recommendation, but with the EU GBS it will become mandatory. As it has been voluntary, issuers have been able to choose if they want to get external verification. For example, issuers with high trustworthiness may not have had a need to get external verification, while investors might ask for external verification from issuers that are less trustworthy. Furthermore, the EU GBS will require external verification both for pre-issuance and post-issuance. This means that even issuers who have paid for external verification will get an additional cost as there will now be two external verifications needed.

"The mandatory exposed allocation report verification adds another cost. So, we are already paying for this pre-issuance. So now we would also be paying for this exposed allocation report verification so it is an additional cost to issue and a potential barrier to entry of the market and this kind of verification is not currently mandatory under ICMAs Green Bond Principles and benefits could be quite small because anyway all the projects have to be listed publicly that is something the standard requires." (D)

Also, many of the interviewees point out that other costs relating to the reporting will appear. To document full compliance with the standard and the taxonomy for a wide range of projects will be costly. The additional costs are argued to affect countries, and companies and some market participants might have a hard time to get to the market because of the high costs. Therefore, the added costs are seen as a market barrier and mentioned as challenges by several issuers.

"There are not many countries that has the recourses to report in line with the EU Taxonomy and the EU standard." (A)

"And as far as we can understand to be able to actually document full compliance with taxonomy for a really vide range of projects, it is going to be extremely costly." (C)

Lack of Initiative (LI). Lastly, what has been pointed out in some interviews is the combination of more costs and requirements and the lack of initiatives. When there are more costs, both for the issuer and for the investor, there is a need for incentives. The issuer needs to have more reporting done and the investor needs to provide more documentation as well regarding the green project. If there are no incentives for the extra workload, it might be more profitable for issuers to continue to issue green bonds aligned with the GBP instead and continue with their old processes.

"The heavy bourdon of documentation of all these criteria that we do not currently document and on the other side no incentives or no sweetening pill, that is a challenge." (D)

Interviewee D further comments that they have given a margin discount to their investors in order to give them incentives and reward them for the work they need to do, such as providing data for the reporting. The taxonomy which is aligned with the EU Green Bond Standard might cause problems regarding this margin discount in the future. If the taxonomy changes, one investment that has been seen as green might not be green anymore and the discount 
cannot be granted any longer. The uncertainty could therefore lead to less green investment while investors are not willing to take the risk. This is especially true for investors with long-term and large investments.

These three market barriers are seen by the Nordic green bond issuers to slow down the development and growth of the green bond market. The requirements and costs will only be higher, but the incentives for issuing EU green bonds are lacking. It has been argued that these market barriers may cause the green bond market to shrink instead of grow.

"Maybe this will instead of shifting over money to green assets through the green market, this will do the opposite. Slow down the transition to green." (F)

"The pure or the real intention by the EU, I am sure that they really are doing this because they hope to grow the market. So, the intention is good. It is just that hopefully it goes that way and we are not killing the market so to say." (I)

\section{Implementation}

Nordic Green bond issuers highlight the several factors that will be relevant in the implementation of the EU Green Bond Standard. The three factors are Adoption Time (AT), Sustainable Reputation (SR) and Investor requirements (IR).

Adoption Time (AT). The common understanding among the interviewees of the adoption of the EU Green Bond Standard is that it will take time for issuers to be able to adopt. The standard is still being established and the process for issuers to align and make sure that everything is done correctly will require time. It will still be possible for issuers to issue green bonds under the alignment of GBP and therefore Nordic green bond issuers believe that only a few EU green bond issuers will be on the market in the beginning. Several Nordic issuers have argued that the GBP has functioned well and believe that there will be, and it is needed to be a parallel system with the GBP and the EU GBS the coming years.

"I think that EU green bonds and known EU green bonds will exist side by side for quite some time. Because I think issuers will struggle to find the assets and be able to demonstrate alignment with all this all the criterion in the taxonomy. And I do believe that part of the market that will be EU green bonds verified will be very small at a beginning." $(\mathrm{C})$

As already mentioned, the EU GBS have stricter and more requirements than the GBP. Therefore, Nordic green bond issuers highlight that issuers may struggle with the requirements. The alignment to the taxonomy is seen as hard to demonstrate and issuers will need time to do appropriate research before issuing an EU green bond. Additionally, a definition of green will be provided in the taxonomy, which might cause issues when it comes to finding eligible assets. All assets that are now called green will not reach the requirements of the taxonomy and therefore issuers will have to make sure that they have suitable assets before they can issue an EU green bond.

"I think issuers will struggle to find the assets and be able to demonstrate alignment with all this all the criterion in the taxonomy." (C)

It is mentioned in the data set that the first adopters will probably be bigger institutions, such as supernationals, with more resources available. There are three main arguments for the bigger institutions to take the lead. Firstly, more resources are needed to be able to comply with the EU Green Bond Standard and bigger institutions have more 
resources both capital wise and knowledge wise. Secondly, these bigger institutions have been heavily involved in the making of the standard and might be able to comply easier as they might have a greater understanding of its content and may have been able to influence the standard to a bigger extent. Thirdly, they might feel pressure from the society and their investors to be in the forefront and issue EU Green bonds in an early stage as they are bigger institutions.

"What I think is going to happened is that you have certain institutions like EIB who are very close with $\mathrm{EU}$, so they will for sure come out with an EU green standard bond as soon as possible. And then what that means is that all the competitors, the peers ... then there is probably going to be a push from the management that everybody should do it and we need to do it as well because they have done it." (I)

As mentioned, the Nordic green bond issuers think that it will take time before there will be a lot of EU green bonds on the market. When it comes to own issuance, some of the Nordic green bond issuers say that there is not a question of issuing, rather when it will be issued. As the development is going forward, the EU GBS is argued to be a natural next step. Others instead state that EU Green bond issuance is not a given thing and that it depends a lot on the market if they will issue an EU green bond at all. The main argument is that as the green bond issuance have been working well without the standard, there is not a big need for EU green bond issuance. There would have to be a demand for EU green bonds from the investor or more incentives in order for some Nordic green bond issuers to join the EU green bond market.

Sustainable reputation (SR). An advantage that some of the Nordic green bond issuers can see is by complying to the standard, companies can create a better sustainable reputation and show the stakeholders that they are frontrunners in sustainability. The EU GBS' aim is to improve the transparency on the market and enlarge the market. By issuing EU green bonds, issuers can show that they want the same and that they are part of the development of the market. At the same time, they can highlight their green business even more and use it for marketing. For several green bond issuers, this would both be in line with their strategy and strengthen it.

"I think there will absolutely be issuer that will be using the GBS. Since someone wants to be the first and I think this will be a motivation of exemplify that you are the most green or it will definitely work as motivation for many companies to issue EU green bonds, since you then exemplify that you are the best in sustainable finance.” (A)

This might also have a negative effect for those who cannot align to the EU GBS because of the strict requirements. As already mentioned, market barriers have been pointed out and Nordic green bond issuers are afraid that not every issuer will be able to align to the standard mainly because of lack of different resources and not enough of incentives. This might affect the reputation negatively. For example, it has been mentioned that issuers who claim to be sustainable but are not able to align to the standard might get a negative response from investors.

"I think it is fair to say that the GBS compared to the GBP is more comprehensive and maybe you would say more robust framework of reference for issuing green bonds, the questions is obviously is does the link to the EU Taxonomy does that become, does that prove to be too onerous for issuers to live up to, so that you will actually will have a more robust framework or approach, but few issuers will use it because they are not able to align themselves with that. Maybe obviously that will generate some negative push back and then investors will say well you claim to be so sustainable, but yet you can't align to the EU Taxonomy". (G) 
"I guess at some point investors start asking so all your peers are there, why do not you issue a green bond aligned with the taxonomy?" (I)

However, even though some Nordic issuers see the EU green bond as a way of strengthening their sustainable reputation, others do not see it as that crucial. It has already been argued that Nordic green bond issuers have a good reputation, therefore the Nordic issuers might not feel that the issuance of an EU green bond is of that big of a deal regarding their reputation. Their investors trust them and have been satisfied with the green bonds they issue. For issuers with less trust from their investors and lower green bond frameworks, issuance of EU green bonds could have a bigger importance than for Nordic issuers.

"What we see is that the EU Green Bond Standard could perhaps help support the market in some Europe, but also the world perhaps. Where we see less of this trust expectations from the market, from investors and other stakeholders. We keep very high standards in our green bonds." (C)

Another angle that some issuers see this from is that issuing an EU green bond can be damaging for the sustainable reputation if it is done incorrectly. Some issuers argue that as the requirements increase and get stricter when issuing a green bond under the EU GBS, some issuers might not feel comfortable in issuing EU Green Bonds as they are not certain that they are aligned enough to the taxonomy. Smaller issuers, especially, might have a greater fear as they might not have the same level of knowledge available or capital. The taxonomy has been argued to be hard to grasp and interpret, which will cause concerns of wrong interpretation. Issuers might therefore choose not to issue EU Green Bonds in order not to jeopardise their reputation with issuing an EU Green Bond that in the end does not meet the criterions.

"I am just afraid that if people are not sure that are you aligned, it might be that you hold back, that you are too afraid to say that yes I will do this bond and it is aligned with the taxonomy." (I)

Investor Requirements (IR). Furthermore, the alignment to the standard is argued by the interviewees to depend on the investors and their requirements. If investor in the future will require alignment to the EU GBS, the alignment will be crucial for the issuers. Alignment can be required because investors want to show that they value the level of requirements that EU green bonds will hold and that the investors see the development of the green bond market as important. This will as well create more incentive for issuing EU green bonds, as issuers otherwise might lose investors or not be able to attract as many.

"I think every issuer is looking at this and strive to be comply, but it is still yet to be seen how the market benefits if investor kind of demand it or if they don't demand it." (D)

If investors on the other hand will not require alignment, an adoption will not be as crucial. Several Nordic green bond issuers have argued that the GBP and the existing market practises have been working well. If investors also are of the same opinion, they might not pressure issuers to issue EU green bonds. The value for issuers to issue green bonds that are more costly and have more requirements might not be high enough. Hence without investor requirements, there will probably be less EU green bonds on the market.

"Some investors and market participants want to always be on top of their game and sort of continue to push the market forward I think you expect some to do that. That being said, there will clearly also be others that say okay if we don't have to do it, we are not going to do that. (G) 


\section{Impact}

The last theme that has been found in the data set concerns the impact that the EU Green Bond Standard will have. The theme consists of the four codes: Harmonising EU (HE), Non-EU Green Bond (NGB), Continuous Development (CD) and Own Experience (OE).

Harmonising EU (HE). The interviewees overall view is that a more harmonised EU is desirable and that this standard can support that transition towards that. What has been stressed by most of the green bond issuers is that it is a welcomed standard and a good signal from the European Commission. The Commission has the right intentions, and they do what they can do in order to support the growth of the green bond market, which is to regulate. A positive impact that can be seen with the standard is that it can bring more transparency and credibility to the market as there will be a standardisation of the bonds and everyone issuing EU green bonds will have to follow the same stricter requirements. It will create a common language for Europe and as well to some extent the rest of the world. Harmonisation is also beneficial as it could make the processes smoother and the market function more efficient.

"I think in general all this kind of standardisation is good because then there is more transparency with regards to the supply and demand side. Both know better what is expected. Common rules, common reporting, standards and common criteria I think that it is a good facilitating factor.” (B)

What has been stressed by the interviewees is the importance of transparency for investors. Investors are dependent on the transparency and it is of every issuers' interest to ensure this to the investors. Everything that can be done in order to make the investors even more comfortable is seen as very favourable. Hence, the EU GBS is seen as being welcomed as it may improve the information and dialogue between the issuer and the investor. It has also been mentioned that greater transparency can prevent greenwashing, one of the biggest issues within green finance.

"Especially taking the investors points of view. It is a lot easier that you can rely on uniform standard. Rather than you have to dive into a more detailed and more specific tail made documentation per issuance. I think it is a good way for sort of increasing speed and transparency in the market as a general thing...We are all relying on the support of different investors and I think the most issuers will probably agree to this, that the more we can do to support the investors processes and transparency, the better." (E)

"It will be a pan European definition of that (what is green) and that I think that is a great thing for investors. That they can be assured that there is this standard that everyone is following or if an issuer is issuing EU Green Bond Standard based bonds, then they are taxonomy aligned, the projects that will be allocated from the bond proceeds. So, it will be easier to compare issuers." (D)

Non-EU green bonds (NGB). Both interviewee A and C emphasised that with the new EU Green Bond Standard and its stricter requirements, the non-EU green bonds might also be affected. Even though they will not be aligned to the EU GBS, non-EU green bonds might strive to keep up with the same quality as EU-Green bonds. Even though green bonds aligned to the GBP will not have the same level of requirements, it will not prevent stricter processes, more documentation, or harder requirements. Therefore, interviewee $\mathrm{A}$ and $\mathrm{C}$ both argue that the non-EU green bond as well will be positively affected by the standard. Further, this means that overall, the green bond markets quality can be seen to go up as all bonds might strive towards higher quality.

"But it will surely affect the IGMA aligned bonds. And the standard for the use of proceeds since the EU green bonds follows the taxonomy has very high criteria, it will surely affect the IGMA-aligned ones as well, to kind of strive for the same criteria." (A) 
"The higher level of quality and verification of the EU Green Bond Standard will also affect the other green bonds in the market. They need to follow sort of, so that will be a positive feature." (C)

However, other interviewees have said that the EU GBS will not affect their issuance of green bonds. This has been argued through the already high level of processes and trust from the investors. In other words, to some extent we might see that green bonds will reach for higher quality.

Continuous Development (CD). A common thought among the Nordic green bond issuers is that it is important to see this as a continuous development. Firstly, the standard is still being drafted and therefore it is hard to say how it will work in reality. Some aspects might not work in practise and may need to be changed and there might be elements that still need to be added. Secondly, development is always needed. That is as well why this standard is being developed. In order to make the standard work well, it is important that it keeps on developing and that the European Commission takes into consideration the market actors' thoughts and experiences also after the establishment. As the green bond market is relatively new, it is logical that the development process needs to keep on developing.

"In my view this is sort of a moving target, the development of the standards and the expectations and criteria. I think it is a moving target because the market is evolving all the time and the investors are generally driving the sort of market to some extent that in sort of defining what is green what is green enough. I think that if we say today that okay this is enough, tomorrow we might have another view on that." (B)

"Hopefully this platform that the commission has now set up to follow up the criteria will also take into consideration some of the experiences from the field in applying these criteria, so that we will end up with a set of criteria that are actually applicable and that actually are feasible to use in the real world of at least financial institutions." (C)

Own Experience (OE). The own experience of issuing an EU green bond is stressed by the overall interviewees. There is a need of own experience before issuers can say exactly how this will work for different companies. As already stated in other themes, there are challenges and advantages that issuers already know about, but there might also be challenges and advantages that may appear along the way. The standard is not established yet and therefore it is hard for the issuers to know how much work it would mean for them to be able to issue an EU green bond. In some cases, the issuers might already have existing processes that may work well, while others may have to start from the beginning. Furthermore, the issuers first need to decide if issuing an EU green bond instead of a non-EU green bond will be more favourable for them.

"It still needs to be turned into some kind of operational things as well and we need to gain experience by complying to this standard. That will take time and obvious there are a lot of lessons that needs to be learned during a more particular phase of working with the EU Green Bond Standard... My take is you would be a bit naive if you think you got everything right in the first place. I think it is a learning process. "(E)

\section{Summary of the findings}

This section has presented the findings from the empirical part of the study. As the questions were opened, there was no case where all the codes were mentioned. However, the participants tended to have more common thoughts than differing thoughts. A summary of the findings can be found below. It has been divided into consistent views among the participants and differing views among the participants. 
Consistent views among the participants. Most of what has been brought up are common views. The two first themes, Company structure and Market barriers are brought up by the majority of the interviewees and the thoughts are similar. The data set shows that there is a difference where the issuers operate geographically, in which sector the issuer are in and the size of the issuer. The Nordic issuers argue for example that they already have a high quality of their green bonds, national regulation and resources are different and that smaller sized issuers will experience more difficulties than bigger sized issuers when issuing an EU green bond. The interviewees also see that there will be added market barriers with the establishment of the standard. Higher requirements, additional costs and lack of initiatives are argued to be the main market barriers. The next two themes on the other hand have more divided views. However, regarding Implementation, the common views are that it will take time before a large amount of EU Green Bonds are on the market, bigger market actors are likely to be the first adopters and requirements from the investors will affect to a large part if and when issuers choose to issue EU green bonds. The common views of the Impact are that harmonisation can be an outcome and is seen as desirable as it can bring transparency and credibility to the market. It is as well emphasized that this is a continuous development also after the implementation and that own experience is necessary in order to know how everything will turn out in practise and not only in theory.

Differing views among the participants. As already discussed, the two first themes did not have many differing thoughts. One view that differs, is whether Nordic issuers will have it easier to apply to the standard. It has been argued that as issuers in the Nordics have come far in the issuance of green bonds it will be easier. At the same time the green building level in the Nordics has harder requirements than in other European countries, which means that all sectors in the Nordics will not have it easier than other countries. When it comes to Implementation the view of Sustainable reputation is differing. Some issuers argue that issuing EU Green Bonds will bring a positive reputation as issuers show that they are frontrunners, while others argue that there is a reputational risk as the requirements are strict and causes a fear of not being aligned enough. Lastly, the differing view regarding Impact relates to non-EU green bonds. It has both been brought up that they might benefit as they will also strive to have the same quality as an EU Green Bond and that no affect will be seen.

\section{Analysis of results}

This section will discuss the empirical findings that were found in the sixth section and connect them with theory and previous literature. The section is divided accordingly to the sub research questions and aims to bring forth the Nordic issuers' views regarding advantages, challenges and the adoption of the EU Green Bond Standard. The results contribute both to theory on standardisation and theory on the green bond market. As already presented in the introduction section, there is one research question of the study, that has been divided into three sub questions:

RQ: What are the Nordic green bond issuers' views on the upcoming EU Green Bond Standard?

1. What kind of advantages do Nordic green bond issuers see with the EU Green Bond standard?

2. What kind of challenges do Nordic green bond issuers see with the EU Green Bond Standard? 
3. What do Nordic green bond issuers think about the adoption of the EU Green Bond Standard?

Wong (2004) has stated in his research that global financial reporting frameworks have several benefits. However, in order for these benefits to be fully realised Wong (2004) argues that the convergence to one set of globally accepted high quality standards need to be greater. The same mindset can be found in Nordic Green Bond issuers. Their response on establishing an EU Green Bond Standard is mainly positive. EU is seen to send out the right signals by working to enhance transparency, integrity, consistency, and comparability of green bonds and as a result enhance the green bond market. However, as Nordic green bond issuers see it right now, there are still several challenges with the standard that could cause market barriers and make it difficult for green bond issuers to issue EU green bonds.

In TEGs (2019) report on EU Green Bond Standard, where the TEG issued its proposal for an EU Green Bond Standard, it was pointed out that the green bond market faces six barriers at the moment. These barriers are all seen as necessary to address in order to develop the green bond market. Interestingly, almost all of these market barriers are still commented as existing challenges even though the EU Green Bond Standard will be established. This will be discussed more in the sub sections below.

Even though most of the Nordic green bond issuers find the standard positive, the focus tends to lie on the challenges it may bring. Hence, there are less advantages discussed than challenges. In some cases, some aspects can be seen as both an advantage and a challenge and will therefore be discussed under both of the sub sections. Also, aspects discussed in the adoption sub section may already have been mentioned and discussed under the earlier sub sections.

\section{Advantages}

Previous literature has shown that improved accountability of information can be created through standards, but it is not certain. Brunsson \& Jacobsson (2000) and Mazhindu and Mafuba (2013) argue that standards can improve the accountability. Behnma \& McgLean (2011) on the other hand concluded that wheter or nor accountability will be improved depends on the kind of. Looking at the data, Nordic green bond issuers instead focus on that the EU GBS will improve transparency and credibility. More requirements and standardisation of the issuance are argued to increase transparency and credibility as everyone will follow the same process which will make it easier to follow. Even though previous studies regarding standard adoption have not emphasized these factors, they are known positive outcomes from standards according to Brunsson \& Jacobsson (2000). As mentioned above, this is as well what the EU GBS standard aims to address.

A definition of what is green has been mentioned to be closely aligned with the improvement of transparency and comparability. As mentioned in the introduction section, the European Commission stated that the fact that there is no commonly agreed definition of green bond and no specific framework is one of the biggest problems when it comes to the development of the green bond market. TEG (2019) has included this as one of the barriers in the development of the green bond market. This is also something that UNEP et. al. (2016) sees as an urgent need. Therefore, it has been argued to be a great indirect outcome from the EU Green Bond Standard. It will be an indirect outcome from the EU GBS because the EU GBS will not itself provide the green definition, but the EU Taxonomy 
will, and the EU GBS requires the alignment to the EU Taxonomy. The Nordic green bond issuers agree and also feel that the green definition is an important part when it comes to enhancing the trustworthiness and the comparability in the green bond market.

The combination of these advantages has been argued to be a step in the right direction in the harmonisation of EU. Several Nordic green bond issuers have commented that harmonisation is desirable. What can be seen is that the advantages that the Nordic issuers see with the EU Green Bond Standard also are applicable with the overall establishment of standards according to Brunsson \& Jacobsson (2000). Furthermore, the Nordic green bond issuers emphasize that everything that can be done in order ease and support investors is favourable. That can be explained with the legitimacy theory. It is important for investors to have the right information and be able to compare and trust the market. Therefore, more reporting is seen as favourable. At the same time, more reporting and requirements are also argued to help decrease greenwashing. As greenwashing is seen as one of the most recognised risks when it comes to green bonds it is seen as favourable. (Ludvigsen 2015).

The EU GBS may also strengthen companies' sustainable reputation. It has been argued that as the EU GBS is the next step in the development of the green bond market, issuing EU green bonds may show that issuers see the development of the market and green finance as important. TEG (2019) has argued that the EU GBS will decrease the reputational risk. KPMG (2019) agrees and argues that issuers can strengthen their ESG related targets and climate commitments by issuing EU Green bonds. When strengthening the ESG data and the credibility of the green bond, KPMG also argue that the reputational risk is expected to alleviate. It is mentioned that issuing EU green bonds may strengthen companies who have sustainability included in their business and/or in their strategy. This can be supported with Mazhindu and Mafuba (2013) results, showing that when the IFRS was adopted, there was a positive impact on building investor confidence. However, it has also been argued that the EU GBS may have negative effects on the reputation. This will be further discussed in sub section 7.2.

It has been mentioned that EU green bonds and non-EU green bonds will coexist on the market in the near future. Even though not all green bonds then will have the same stricter requirements, some Nordic green bond issuers argue that the quality of non-EU green bonds may as well go up. This is due to issuers striving to provide the same quality level of green bonds. This has been supported with the arguments that issuers want to provide the best possible green bonds to the investors, they want to keep developing and be frontrunners. This is something that has not been mentioned in previous literature but can be explained by pressure from stakeholders and a desire to improve the own business.

This research has been focusing on Nordic green bond issuers as Nordic countries are known for being in the front with environmental regulation, societal awareness and behaviour change consistent with the sustainable economy for decades (McCormick, Richter \& Pantzar 2015). Literature has argued that there is a difference of how long the Nordic countries have come in the development of sustainable finance and green bonds (Nassiry 2018). The data also points this out. Nordic green bond issuers overall feel quite confident in a possible adoption of the EU Green Bond standard. As Nordic green bond issuers tend to be in the front line regarding the development of green bonds, the new restrictions are argued as not as hard for them as for others who have not come as far. There are though exceptions, such as issues relating to the real-estate sector. 


\section{Challenges}

According to the European Commission the aim of the standard is to allow the green bond market to grow (TEG 2019). KPMG (2019) also agrees that the benefits that the standard will contribute with are expected to affect in an increase of the financing of green and sustainable projects. Nordic green bond issuers mentioned several times in the interviews that the standard has the right intentions, allowing the market to grow. The Nordic issuers are however worried that it instead will make the market smaller because the requirements will be too hard. Wong (2004) mentions this as one challenge as well in his research when it comes to implementing standards. It is an issue of scale which means that implementation barriers associated with the relative cost of compliance for small- and medium-sized entities occur.

What can be found as striking is that the six barriers for the development of the green bond market: (1) Lack of eligible green projects and assets, (2) Issuer concerns with reputational risk and green definitions, (3) Absence of clear economic benefits for issuers, (4) Complex and potentially costly external review procedures, (5) Labour intensive reporting procedures, (6) Uncertainty on the type of assets and expenses that can be financed, that TEG (2019) pointed out in their report on EU Green Bond Standard, still all except the sixth barrier to some extent have been mentioned as challenges that Nordic green bond issuers see now when the EU Green Bond Standard is being established. These barriers were brought up by TEG in their report to strengthen the need of the EU Green Bond Standard and the standard aims to address the barriers.. Still Nordic green bond issuers see these as challenges after the establishment of EU GBS.

The first barrier that TEG (2019) brings up is lack of eligible green projects and assets. The EU GBS is meant to help by, through the alignment with the Taxonomy, define what green is. When defining what green is, it should be easier for issuers to find suitable green assets. However, some Nordic issuers argue that as not all assets that are now called green assets will meet the new requirements, there might instead be a decrease in green assets and hence it will be even harder to find green assets. For example, it was mentioned that the Nordic green buildings will not meet the high requirements and therefore if the EU GBS will follow the draft, there will not be any Nordic EU green bonds from the real-estate sector.

Issuer concern with reputational risk and green definition is the second barrier that TEG (2019) emphasises. As mentioned in the previous sub section, both TEG (2019) and Nordic green bond issuers point out that the EU GBS through the taxonomy will provide a definition of green. However, the Nordic green bond issuers are worried that the EU GBS still leave issuers with concerns and reputational risk, as there will still be a risk with the interpretation of the standard. Issuers may issue an EU Green bond with the belief of being fully aligned, but in the end not being aligned enough. This is in line with Wong (2004) who argues that one potential challenge when adopting a standard is the issue of understandability. Issuing a green bond without being completely aligned is seen to instead of creating a stronger reputation, weaken the reputation. This has also been seen in Aravind and Christmann's (2011) findings. They have stated that when the quality of the standard implementation is low, the signalising of good environmental responsibility will be weakened. 
The market barrier related to the absence of clear economic benefits for issuers is also seen to still be a problem. Wong (2004) brought up the issues of incentives in his research as one challenge with adopting and implementing standards. It has been argued that in order for the market to grow, there needs to be more incentives. UNEP et. al. (2016) agree and think that incentives are important in order to decrease the cost of capital for green project, increase investor certainty and catalyse investment capital into green investments. Nordic issuers argue that one challenge with the new standard is that there are more requirements, but not necessarily incentives. Without incentives it might be harder to argue why issuers should issue EU Green Bonds when they still can give out green bonds that are aligned with the green bond principles. In TEGs (2019) report however, possible incentives that can support the EU Green Bond Market have been included. It seems that even though the goal with the standard is to get clearer economic benefits, Nordic green bond issuers are not certain if that will be the case.

The next barrier, complex and potentially costly external review procedures does not either seem to have been tackled with the EU GBS according to the Nordic green bond issuers. The GBP has only recommended an external review, but the EU GBS will require external reviews. TEG (2019) argues that the barrier is due to that there is a broad range of market practices and levels of competences when it comes to external reviews. When including mandatory standardised external reviews and the requirement of specific accredited reviews in the EU GBS, costs should be kept low and the process should be more smoother and easier to follow. KPMG (2019) agree and see improvements regarding the varying quality and extent of external reviews. However, the Nordic green bond issuers do see the additional costs with mandatory external review. It has been argued that this will mainly only bring more costs and bureaucracy for the issuers. For Nordic green bond issuers, it is viewed as more of a burden than something that adds value because of the already high quality of green bonds and high level of trust from the investors. For smaller market actors on the other hand, this is argued to be a bigger challenge as they do not have the same level of resources. The cost might be too high both capital wise and knowledge vice. The lack of capacity and lack of knowledge for small and medium sized firms was also pointed out by Mazhindu and Mafaba (2013) as a challenge when adopting IFRS.

Labour-intensive reporting procedures were brought up as another barrier for the development of the green bond markets. This issue relates to a big extent to the previous barrier. With the establishment of the EU GBS, KPMG (2019) mentioned that the standard may cause extra work, but that the positive outcomes from the standard will be higher. The data however shows that Nordic green bond investors see this as a significant aspect and a challenge for issuers. The additional costs that the standard will require, such as reporting costs and external verification costs, are argued to make it more complicating and the market more excluding as smaller issuers and new issuers will not have the resources that are needed. Both Mazhindu and Mafaba (2013) and Wong (2004) have as well emphasised that smaller entities will face more challenges than bigger entities due to less resources. This is as well one of the reasons why Nordic green bond issuers are afraid that the green bond market will shrink instead of grow.

In addition to the barriers that TEG (2019) mentioned, the Nordic green bond issuers bring up some additional challenges. One of the biggest challenges that the Nordic green bond issuers see is the alignment with the EU Taxonomy. As the EU Green Bond Standard will be aligned to the EU Taxonomy, all its requirements will need to be met. This relates to some part with the labour-intensive reporting procedure barrier. One of the requirements, Do 
no significant harm is seen as a challenge in particular for issuers that operate in several industries or are in the financial sector. National legislation and EU legislation will not be sufficient to rely on for the Do no significant harm criteria as some countries may have less strict laws than what the requirements are in the taxonomy. This can be supported with Wong (2004) research where he also emphasized the issue of regulation when adopting standards. This means that a more thorough process would need to be done, which is stressed as both difficult and costly. Especially if the issuers are not the ones who will be using the proceeds, as is the case of financial institution. The issuers then need to make sure that all of its customers have the requirements in order. In other words, this relates to costly and complex requirements that already have been mentioned as common challenges when it comes to adoption of standards.

Furthermore, some Nordic green bond issuers see the grandfathering of the bonds as challenging. As the draft is written now, the bonds will be grandfathered and stay as an EU green bond until maturity. This will cause challenges for issuers using a portfolio approach when allocating proceeds. The problem with this is that the underlying assets will not be grandfathered, and if the requirements in the Taxonomy change for green assets, the underlying assets of the EU green bonds need to be reassessed. It is stated in TEG's Final report on the EU Taxonomy that this will be done from year to year (TEG 2020). Again, this will be costly and require additional work for the issuers.

Even though TEG (2019) states that the EU GBS should be open to all type of issuers, the data shows that Nordic green bond issuers see it as a challenge to make the standard applicable and fair for every issuer. This can also be seen in previous literature, Wong (2004) has included challenges associated with cultural barriers and challenges associated with regulations. One point that was already mentioned is that as EU is a large area of countries the national laws differ from each other and that will cause some problems. An example that came up in the interviews are the requirements for green buildings. They are now set on a level that make it almost impossible for Nordic real-estate companies to issue green bonds. This is due to the fact that the requirements to get an A level certificate for buildings are higher in Nordic countries than in other countries and the EU Taxonomy requires A level buildings to get to use the proceeds as a green project.

The size of the entity also plays a role in the applicability of the standard. As discussed earlier, smaller companies will experience more difficulties to adopt the standard than bigger companies. Smaller companies have less resources and might not be able to issue a green bond with these extra requirements. The fear of not understanding the standard well enough is also argued to be more for smaller companies, as they may have less knowledge and human resources that can be invested in the issuance. Bigger institutions on the other hand have more resources and they have been argued to have been more involved in the establishment of the standard. Therefore, the standard is argued to be easier to adopt for bigger actors than for smaller actors.

It is pointed out that the EU Green Bond Standard has been developed from an Eurocentric perspective. When forming the standard, consultations have been made and market participants have been able to share their thoughts. Some market players have been seen to have been more involved than others and the concern of the standard being biased has been raised. KPMG (2019) states that the European Green Bond Standard will be both an official European and international standard. This is also one of the standards aims (TEG 2019). Nordic green bond issuers are though concerned that when creating the standard, the country differences have not been kept enough in mind. It was brought 
up that national regulation might be a problem as all countries' laws are different. For example, regarding green buildings or the no significant harm criteria. Furthermore, countries outside of EU do not comply with EU regulation and therefore it might cause problems when aligning to the EU Green Bond Standard. This is also one of the issues that Wong (2004) brings up regarding adoption and implementation of international standards. Brunsson \& Jacobsson (2000) further comments that how well the standard turns out depends on if the standardizers know what is best for everyone that will follow the standard.

\section{Adopting the standard}

When it comes to the need of an EU Green Standard, previous literature has stated that there is a need of the standard and that it is a natural part of the development of the green bond market (UNEP et. al. 2016). Overall Nordic green bond issuers also think that the standard is a good initiative. However, regarding the need of an EU Green Bond Standard, the answers are more divided. Some Nordic green bond issuers argue that the green bond principles have been enough, they have given the support that has been needed at the same time as the issuers have had enough freedom. According to Brunsson and Jacobsson (2000) the lack of freedom that standards may cause is also one of the main arguments against standards. However, other Nordic green bond issuers argue that this is a natural next step towards a bigger green bond market. With these thoughts in mind, it is as well natural that some issuers will adopt and issue EU Standard Green Bonds early and some later, or even never.

As the standard is in the establishing stage, there is still a lot of uncertainty about the adoption. Some Nordic issuers state that the question is not if they will issue an EU standard green bond, instead it will only be a matter of time before they will. Other Nordic issuers state that nothing is certain and that it depends on several aspects, such as investor requirements. The investor requirements can be explained through the legitimacy theory. If investors see the alignment to the EU Green Bond Standard as desirable or even mandatory in order for them to invest, issuers would feel pressure to start issuing EU Green Bonds in order to ensure that they operate according to new norms of the society.

Due to that Nordic issuers are frontrunners when it comes to green finance, some green bond issuers have argued that the alignment to EU GBS may not be needed as their trustworthiness already is high enough. This relates as well to the investors' requirement, if the investors feel that the reporting processes that are now used are also enough in the future then alignment to the EU BGS might not be as crucial. Instead, some Nordic green bond issuers have stated that other countries in the EU or worldwide, with a lower requirement, would have more use for the standard.

The reputational risk has already been discussed in the previous sub sections. Issuing an EU green bond can both be positive and negative for companies' reputation. Therefore, the reputational risk has been argued to affect the adoption of the standard. If issuers feel that aligning to the EU GBS will improve their reputation by showing that they are front runners and want to ensure high quality green bonds as TEG (2009) and KPMG (2019) argue, the adoption is more likely. If issuers on the other hand still feel that the reputational risk exists, issuers are less likely to issue EU green bonds. This is due to fear of not being aligned enough and hence experience negative reputation and can be supported by Aravind and Christmann (2011) research. 
Nordic green bond issuers foresee the bigger institutions, such as supernationals, to be the first ones to issue EU green bonds. This can be argued due to the fact that they are seen to face less of the challenges mentioned above and have the right prerequisite. Firstly, they have the resources needed, both money wise and people wise, as more resources will be demanded. Secondly, they have been in close collaboration with the establishment and therefore they have more knowledge and may feel more secure than others regarding the reputational risk. Thirdly, what can be argued is that they have been able to affect the outcome to a further extent due to the close collaboration and might therefore as well face less challenges. Lastly, they might be facing more pressure from the investors as they are bigger actors on the market.

\section{Conclusions and implications}

This section will present the five key conclusions of the research followed by suggestions on further research. The research aims to contribute to literature on both standardisation and the green bond market. The study has been done through the eyes of market leading actors: Nordic green bond issuers. As Nordic issuers are active and have been on the market since the start, their views should be seen as important.

\section{Key conclusions and contribution}

Previous literatures' key findings on new standards show that there are both advantages and challenges when adopting a new standard. The main advantages that have been seen are an increase of accounting quality, positive reaction on companies' reputation, and positive financial outcomes. Overall, the market reacts positively to new standards. Challenges that have been pointed out in previous literature are to a far extent a lack of either knowledge or resources. Furthermore, the complexity that standards may bring is seen as especially hard for small- and medium-sized firms. When it comes to the adoption of standards, low adoption can be seen due to lack of basic accounting financial knowledge and low level of encouragement from policy makers. Additionally, the implementation quality of a standard has been seen to affect certified facilities' environmental performance, as low implementation quality results in weakened improvement of environmental performance and lower signalising of good environmental responsibility.

The five key conclusions that can be found regarding Nordic green bond issuers' views on the upcoming EU Green Bond Standard:

1. The Nordic green bond issuers are positive to the initiative of establishing the EU Green Bond Standard.

What can be concluded is that Nordic green bond issuers are positive to the initiative of establishing the EU Green Bond Standard. This is in line with the feedback TEG got on their interim report. Even though the GBP and the existing market practises overall have been seen to work well, the EU GBS is welcomed and has a good aim to harmonise the EU market and enlarge the green bond market. It is seen as a strong signal from the European Union and as a natural part of the development of the market. This finding contributes to the literature on standardisation by confirming that standards can be used to harmonise markets. It also adds to the literature on the green bond market by stating that a standard is seen as suitable to develop the green bond market. 
2. The challenges seen by the Nordic green bond issuers with the drafted EU Green Bond Standard are to a far extent known challenges that the EU BGS aims to address.

The Nordic green bond issuers see several challenges with the establishment. Challenges that to a far extent already were known challenges by the TEG and which the EU commission aims to address with the EU Green Bond Standard. Even though the challenges have been brought up, the Nordic green bond issuers still see them as existing challenges and do not see that the standard, as it is written now, will improve them. Challenges that are mentioned are the alignment to the EU Taxonomy, which will bring higher requirements, additional costs relating to the added requirements, such as labour intense reporting procedures and external reviews, reputational risk and lack of incentives. This shows that more effort should be put on addressing the known challenges and clarifying how the EU GBS will help to improve them. It is seen as important that the standard is clear in order to limit the uncertainty the added requirements may bring. The potential incentives that relate to the EU GBS would need to be overlooked and implemented in order for issuers to get more motivation to issue EU green bonds.

3. The Nordic green bond issuers argue that the drafted EU Green Bond Standard is not fair and applicable for all countries.

Challenges that have not been brought up earlier regarding the standard is the fairness of it for all issuers. Nordic green bond issuers point out that it has been developed from an Eurocentric point of view and therefore issues might occur as the countries' differences have not been taken enough into consideration. For example, green buildings in the Nordic have higher requirements regarding certificate levels than other countries, which means that Nordic issuers within the real-estate sector might not be able to issue green bonds. This finding adds to the existing literature by emphasising the challenge of creating fair and applicable standards for all users. It also signalises that there is a need of continuous development of the standard to make sure that it stays relevant, something that both the European Commission and the Nordic green bond issuers have brought forward. Furthermore, Nordic green bond issuers point out that smaller issuers will have more difficulties to issue EU green bonds because of the high requirements and hence might get excluded from the market. This finding supports Wong (2006) finding that there is an issue of scale when implementing standards. Therefore, it is important for the standardisers to note and to support the smaller entities in their adoption.

4. If the challenges are not taken into consideration, Nordic green bond issuers argue that the establishment of the EU Green Bond Standard may not enhance the green bond market, but instead shrink the green bond market.

One of the aims with the EU GBS is to enlarge the green bond market. Previous literature shows that standards may contribute to a positive market reaction. Still, many Nordic green bond issuers are worried that if the challenges mentioned in section 7.2 are not taken into consideration, the green bond market might not be enhanced, but instead it might shrink. This finding contributes to the existing literature on standardisation by highlighting the challenge of 
creating a balanced standard with enough requirements to improve the standard and the transparency of the product, but also with enough space for own interpretation to ensure that market participants have the possibility to align. Therefore, in order for the EU Green Bond Standard to serve its purpose there is a need to look over the usability of the standard so that stakeholders are able to align to it.

5. The adoption of the EU Green Bond Standard is not a guarantee for issuers.

Nordic green bond issuers see that there will be different views whether to adopt the standard or not. As the GBP will continue to coexist, alignment to the EU GBS is not guaranteed and is not seen to happen overnight. Bigger institutions are recognised as early adopters, as they have more resources, they might have been more involved in the establishment process of the standard and they may have more pressure from investors. Key drivers for other green bond issuers to issue EU green bonds and requirements from their investors and positive impact on their reputation. Key drivers to not issue EU green bond is the already high quality of green bonds, the higher requirements and costs and the fear of not being aligned enough and experience negative impacts on their reputation. This finding shows that standard adoption is not guaranteed and contributes to the literature on standard adoption by presenting the key drivers for adopting the standard or for not adopting the standard. Additionally, bigger issuers, such as supernationals, have been pointed out as early adopters.

\section{Suggestions for further research}

As the EU Green Bond Standard is now being established, the opportunities for further research are many. Firstly, the research can be broadened by looking into other EU countries and compare them to the Nordics. It would also be possible to look into whether countries outside the EU see this as a potential international standard. Secondly, when the standard is established, it would be of interest to look into how the adoption of the standard is going. Are issuers adopting the standard and what are the main arguments of either doing so or not? Also, when the standard has been out for a while, have the market barriers and challenges that already have been brought up been changed? After the standard has been in place and EU green bonds have been issued it would as well be interesting to see if there are any price differences of the bonds and if the companies are seeing some market reactions from other stakeholders.

\section{References}

Adams, C. A., Hill, W. Y. and Roberts, C. (1998). Corporate Social Reporting Practices in Western Europe: Legitimating Corporate Behaviour? British Accounting Review. 30 (1), 1-22.

Armstrong, C. Et al (2008). Market Reaction to the Adoption of IFRS in Europe. The Accounting Review. 85 (1), $31-61$.

Aravind, D., \& Christmann, P. (2011). Decoupling of Standard Implementation from Certification: Does Quality of ISO 14001 Implementation Affect Facilities' Environmental Performance? Business Ethics Quarterly. 21(1), 73-102.

Barth, M., Landsman, W. and Lang, M. (2006). International Accounting Standards and Accounting Quality. Journal of Accounting Research. 46, 467-498.

Behnma \& McgLean (2011). Where is the Accountability in International Accountability Standards?: A Decoupling Perspective. Business Ethics Quarterly. 21 (1), 45-72.

BIS (2020). Green bonds and carbon emissions: exploring the case for a rating system at the firm level. BIS Quarterly Review. Available: https://www.bis.org/publ/qtrpdf/r_qt2009c.htm. Accessed: 22.11.2020. 
Braun, V. \& Clarke, V. (2012). Thematic analysis. In H. Cooper, P. M. Camic, D. L. Long, A. T. Panter, D. Rindskopf, \& K. J. Sher (Eds.), APA handbook of research methods in psychology, Vol. 2: Research designs: Quantitative, qualitative, neuropsychological, and biological (pp. 57-71). Washington, DC: American Psychological Association.

Brunsson, N. \& Jacobsson B. (2000). A world of standards. Oxford: Oxford University Press.

Burlea-Schiopoiu, A. \& Popa, I. (2013). Legitimacy Theory. Encyclopedia of Corporate Social Responsibility. SpringerVerlag: Berlin Heidelberg.

Bryman, A. (2012). Social Research Methods. Fourth edition. New York, Oxford University Press inc.

Campbell, D., Craven, B. and Shrives, P. (2003), "Voluntary social reporting in three FTSE sectors: A comment on perception and legitimacy". Accounting, Auditing and Accountability Journal. 16 (4) 558-81.

CBI (2018). The green bond market in the Nordics. Available: https://www.climatebonds.net/system/tdf/reports/cbi-nordicsfinal-03b.pdf?file=1\&type=node $\&$ id $=33492 \&$ force $=0$. Accessed: 10.11 .2020 .

Climate Bonds Initiative (2021). Record \$269.5bn green issuance for 2020: Late surge ses pandemic year pip 2019 total by $\$ 3 b n$. Available: https://www.climatebonds.net/2021/01/record-2695bn-green-issuance-2020-late-surge-sees-pandemic-yearpip-2019-total-3bn. Accessed: 4.4.2021

COM/2019/640 final.

Deegan, C., Rankin, M. and Tobin, J. (2002), “An Examination of the Corporate Social and Environmental Disclosures of BHP from 1983-1997: A Test of Legitimacy Theory”. Accounting, Auditing and Accountability Journal, 15 (3), $312-43$.

Delmas, M. \& Burbano, V. (2011). The drivers of greenwashing. University of California, Berkeley, 54 (1).

Dowling, J. and Pfeffer, J. (1975), “Organizational legitimacy: Social values and organizational behaviour”. Pacific Sociological Review, 18 (1), 122-36.

EIB (2016). Green Bond market development and EIB. Available: https://www.eib.org/attachments/green-bond-marketdevelopment-and-eib.pdf. Accessed: 5.1.2021.

EU HLEG (2018). Final report by the High-Level Expert Group on Sustainable Finance.

European Commission (2020). Commission action plan on financing sustainable growth. Available: https://ec.europa.eu/info/publications/sustainable-finance-renewed-strategy_en. Accessed: 3.10.

European Commission a (n.d). A European Green Deal. Available: https://ec.europa.eu/info/strategy/priorities-20192024/european-green-deal_en. Accessed: 3.10.

European Commission b (n.d.). EU Green Bond Standard. Available: https://ec.europa.eu/info/business-economy-euro/bankingand-finance/sustainable-finance/eu-green-bond-standard_en. Accessed: 30.10.2020.

European Commission c (n.d). European Standards. Available: https://ec.europa.eu/growth/single-market/europeanstandards_en. Accessed: 15.11.

European Commission d (n.d.) Aaris Available: https://ec.europa.eu/clima/policies/international/negotiations/paris_en. Accessed: 1.10.2020.

European Commission a (2019). Financing sustainable growth. Available: https://ec.europa.eu/info/sites/info/files/business_economy_euro/banking_and_finance/documents/200108-financingsustainable-growth-factsheet_en.pdf. Accessed: 1.10 .2020 .

European Commission b (2019) Report on EU Green Bond Standard. Available: https://ec.europa.eu/info/sites/info/files/business_economy_euro/banking_and_finance/documents/190618-sustainablefinance-teg-report-green-bond-standard_en.pdf. Accessed: 1.11.2020.

Fatica, S., Panzica, R. \& Rancan M. (2019). The pricing of green bonds: are financial institutions special? JRC Working Papers in Economics and Finance, No. 2019/7.

Fisher et al. (2017). Legitimate to whom? The challenge of audience diversity and new venture legitimacy. Journal of Business Venturing, 32, 52-71.

Freeman R.E. (1984). Strategic Management: A stakeholder Approach. Boston, MA:Pitman.

Ghauri, P. \& Grønhaug, K. (2010). Research Methods in Business Studies. Fourth Edition. Harlow: Pearson Education Limited.

Guthrie, J. et al. (2006). Legitimacy theory: a story of reporting social and environmental matters within the Australian food and beverage industry. Proceedings of the fifth Asia Pacific Interdisciplinary Research in Accounting Conference.

ICMA (2018). Green Bond Principles: Voluntary Process Guidelines for Issuing Green Bonds. Available: https://www.icmagroup.org/assets/documents/Regulatory/Green-Bonds/Green-Bonds-Principles-June-2018-270520.pdf. Accessed: 28.9.2020.

Jakubik, P. and Uguz, S. (2020). Impact of green bond policies on insurers: evidence from the European equity market. Journal of Economics and Finance, 1-13.

Jenner, B. \& Myers, K. (2019) Intimacy, rapport, and exceptional disclosure: a comparison of in-person and mediated interview contexts. International Journal of Social Research Methodology, 22(2), 165-177.

Karamanou, I. and G. Nishiotis. (2005). The Valuation Effects of Firm Voluntary Adoption of International Accounting Standards. Working paper, University of Cyprus.

KPMG (2019). EU Sustainable Finance explained - Green Bonds. Available: https://home.kpmg/fi/fi/home/Pinnalla/2019/11/eusustainable-finance-explained-green-bonds.html. Accessed: 15.11.2020. 
KPMG (2017). KPMG Survey of corporate responsibility reporting $2017 . \quad$ Available: https://assets.kpmg/content/dam/kpmg/xx/pdf/2017/10/kpmg-survey-of-corporate-responsibility-reporting-2017.pdf. Accessed: 3.10.2020.

KPMG (n.d.). EU's taxonomy for sustainable finance. Available: https://home.kpmg/se/sv/home/tjanster/radgivning/sustainablefinance/align-your-investments-with-eu-taxonomy-for-sustainable-finance.html. Accessed: 15.11.2020.

Kirk, J. \& Miller, M. (1986). Reliability and Validity in Qualitative Research. First edition. London: SAFE Publications.

Krouwel, M., Jolly, K. \& Greenfield, S. (2019). Comparing Skype (video calling) and in-person qualitative interview modes in a study of people with irritable bowel syndrome - an exploratory comparative analysis. BMC Med Res Methodol, 19, 219.

Liu, Z. (2020). Unraveling the complex relationship between environmental and financial performance - A multilevel longitudinal analysis. International Journal of Production Economics, 219, 328-340.

Ludvigsen, P. (2015). Advanced topics in green bonds: Risks. Environmental Finance. Available: https://www.environmentalfinance.com/content/analysis/advanced-topics-in-green-bonds-risks.html. Accessed: 15.12.2020.

Mazhindu, K. \& Mafuba, G. (2013) The adoption of international reporting standards for small to medium enterprises in Zimbabwe. International Journal of Asian Social Science, 3(11), 2315-2349.

McCormick, K., Richter, J. L., \& Pantzar, M. (2015). Greening the Economy Compendium. Lund University.

Nassiry, D. (2018). Green Bond Experience in the Nordic Countries. ADBI Working Paper 816. Tokyo: Asian Development Bank Institute.

Nordic Public Sector Issuers (2020). Position Paper on Green Bonds Impact Reporting. Available: https://kommuninvest.se/wpcontent/uploads/2020/02/NPSI_Position_paper_2020.pdf. Accessed: 5.11.2020.

Patton M.Q. (2015). Qualitative research \& Evaluation Methods. Thousand Oaks: Sage Publication.

Podsakoff, P. Et al. (2003). Common method biases in behavioural research: A critical review of the literature and recommended remedies. Journal of Applied Psychology, 88(5), 879.

Ponterotto, J.G. (2005). Qualitative research in counselling psychology: A primer on research paradigms and philosophy of science. Journal of counselling psychology, 52(2), 126-136.

Preclaw, R \& Bakshi, A. (2015). The cost of Being Green. Barclays. Available: https://www.environmentalfinance.com/assets/files/US_Credit_Focus_The_Cost_of_Being_Green.pdf. Accessed: 22.11.2020.

Scott, D. (2003). Wall Street Words: An A to Z Guide to Investment Terms for Today's Investor. 3rd edition. Boston: Houghton Mifflin Harcourt.

Silverman, D. (2011). Interpreting qualitative data: A guide to the principles of qualitative research. London: SAGE

Suchman, M. (1995). Managing Legitimacy: Strategic and Institutional Approaches. The Academy of Management Review, 20, 571-610.

S\&P Global (2019). Green Bond Issuance: Setting Records. Available: https://www.spglobal.com/en/researchinsights/articles/green-bond-issuance-setting-records. Accessed: 22.11.2020.

Talbot, K. (2017). What Does "Green" Really Mean?: How Increased Transparency and Standardization Can Grow the Green Bond Market, Villanova Law Environmental Law Journal, 28, 127.

TEG (2020). Final on the EU Taxonomy. Available: https://ec.europa.eu/info/sites/info/files/business_economy_euro/banking_and_finance/documents/200309-sustainablefinance-teg-final-report-taxonomy_en.pdf. Accessed: 19.1.2021.

TEG (2019) Proposal for an EU Green Bond Standard - Interim Report. Available: https://ec.europa.eu/info/sites/info/files/business_economy_euro/banking_and_finance/documents/190306-sustainablefinance-teg-interim-report-green-bond-standard_en_0.pdf. Accessed: 21.11.2020.

TerraChoice (2007). Sins of Greenwashing. Available: https://www.ul.com/insights/sins-greenwashing. Accessed:22.11.2020.

The World Bank (2015). What are green bonds?. http://documents.worldbank.org/curated/en/400251468187810398/What-are-green-bonds. Accessed: 28.10.2020.

UNEP et. al. (2016). Green finance - A growing imperative. Available: http://unepinquiry.org/wpcontent/uploads/2016/05/Green_Finance_A_Growing_Imperative.pdf. Accessed: 1.4.2021.

United Nations (n.d.). The 17 goals. Available: https://sdgs.un.org/goals. Accessed: 1.10.2020.

Vigneau, L., Humphreys, M. and Moon, J. (2014). How do firms comply with international sustainability standards? Processes and consequences of adopting the global reporting initiative. Journal of Business Ethics. 131 (2), 469-486.

Werther, W. \& Chandler, D. (2011). Strategic Corporate Social Responsibility: Stakeholders in a Global Environment. Sage Publication. Inc., USA.

Wong, P. (2004). Challenges and successes in implementing international standards: achieving convergence to IFRSs and ISAs. International Federation of Accountants. Available: https://www.cimaglobal.com/Documents/ImportedDocuments/ifac_report_challengesuccess_111004.pdf. Accessed: 15.11.

Zimmerman, M.A. and Zeitz, G.J. (2002) Beyond Survival: Achieving New Venture Growth by Building Legitimacy. Academy of Management Review. 27, 414-431.

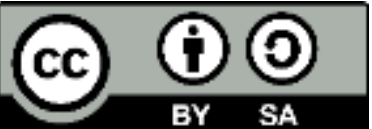

(C) 2021 by the authors. Licensee ACRN Publishing, Austria, Editor in Chief Prof. Dr. Othmar M. Lehner. This article is an open access article distributed under the terms and conditions of the Creative Commons Attribution (CC BY SA) license (https://creativecommons.org/licenses/by-sa/4.0/) 


\section{Appendix 1 Interview guide}

What is your role in the company?

How long have you been working with green bonds?

For how long has your company/organisation been issuing green bonds?

How often does your company issue green bonds?

Are green bonds an important part of your business?

Are you familiar with the EU Green Bond Standard?

What are your initial thoughts about the EU Green Bond Standard?

Do you feel that there is a need for a united green bond standard in EU?

Do you think that the Green Bond Principles and the existing market practice have been enough?

Have you encountered issues when issuing green bonds that you think will be solved with an EU Green Bond Standard?

Do you feel that a green bond standard will affect green bonds?

Are there any advantages with establishing a green bond standard in EU?

Are there any challenges with establishing a green bond standard in EU?

Do you see possible different short term and long-term opportunities and advantages?

Do you feel that the standard has taken the possible challenges and advantages into consideration?

The Standard will be voluntary, do you think that actors will apply to it?

Do you feel that a green bond standard will affect your company?

Are there any advantages for your organisation with the establishing of the EU Green Bond Standard?

Are there any challenges for your organisation with the establishing of the EU Green Bond Standard?

Will the EU Green Bond Standard affect your issuing of green bonds?

The European Commission has done a targeted consultation on the establishment of an EU Green Bond Standard.

Did your organisation take part in this?

Do you feel that there is something missing with the standard?

Do you feel that enough support is given regarding the EU Green Bond Standard?

Are there some final remarks that you would like to add? 


\section{Appendix 2 Acronyms}

$\mathrm{CR}=$ Corporate responsibility

$\mathrm{CSR}=$ Corporate social responsibility

EU GBS = EU Green Bond Standard

$\mathrm{GBF}=$ Green Bond Framework

GBP $=$ Green Bond Standard

ICMA = International Capital Market Association

SDG $=$ Sustainable Development Goals

$\mathrm{SME}=$ Small to medium enterprises

TEG $=$ the EU Technical Expert Group on sustainable finance 